\title{
Light-Induced Calcium Release and Re-uptake in Toad Rods
}

\author{
Gordon L. Fain ${ }^{1}$ and Walter H. Schröder ${ }^{2}$ \\ 1Department of Ophthalmology, Jules Stein Eye Institute, UCLA School of Medicine, Los Angeles, California 90024, and \\ ${ }^{2}$ Institut für biologische Informationsverarbeitung, Kernforschungsanlage, Jülich, D-5140 Jülich 1, Federal Republic of \\ Germany
}

\begin{abstract}
Laser micromass analysis was used to investigate the effect of light on the Ca content of rod outer segments in the isolated retina and eyecup of the toad, Bufo marinus. Isolated retinas were incubated in Ringer for which most of the $\mathrm{Ca}$ (normally $97 \%{ }^{40} \mathrm{Ca}$ ) was replaced with ${ }^{44} \mathrm{Ca}$, so that release of internal $\mathrm{Ca}$ (as ${ }^{40} \mathrm{Ca}$ ) could be distinguished from the uptake of ${ }^{44} \mathrm{Ca}$ from the external medium. Continuous illumination produced a decllne In outer segment ${ }^{40} \mathrm{Ca}$ content. In bright light, the decrease in ${ }^{40} \mathrm{Ca}$ was sigmoidal, beginning with a delay of at least 4 sec, reaching a maximal rate of 1$2 \times 10^{8} \mathrm{Ca} / \mathrm{rod} / \mathrm{sec}$ after 8-16 sec, and declining to zero as the light-releasable pool of ${ }^{40} \mathrm{Ca}$ was exhausted within 1-2 min. Decreases of similar magnitude and time course to those observed in isolated retina were also seen in an eyecup preparation. The rate of light-dependent release was reduced 20 - to 60 -fold by substitution of external Na with choline or $\mathrm{Li}$. The rate of ${ }^{44} \mathrm{Ca}$ uptake from the external medium into rods was little affected during continuous illumination. Uptake, however, was markedly increased in darkness following light exposure. This $\mathrm{Ca}$ re-uptake occurred at a rate approximately 2-fold greater in eyecups than in isolated retinas. We interpret our results to show that light causes an increase in the permeability or transport of $\mathrm{Ca}$ across the disk membrane and that the $\mathrm{Ca}$ is extruded from the rod via $\mathrm{Na} / \mathrm{Ca}$ (or $\mathrm{Na} / \mathrm{Ca}-\mathrm{K}$ ) exchange across the plasma membrane. Cessation of illumination stimulates the resequestration of Ca back into the disks, and this process is somehow enhanced by the presence of the pigment epithelium.
\end{abstract}

Yoshikami and Hagins (1971) first suggested that $\mathrm{Ca}$ might function as an internal messenger in rods, directly regulating the opening and closing of the light-dependent channels in the outer segment. Although therc is now cxcellent evidence that the channels are gated during transduction not by $\mathrm{Ca}$ but rather by cGMP (Fesenko et al., 1985; Matthews and Watanahe, 1987; Nakatani and Yau, 1988b), recent evidence indicates that Ca nevertheless plays an essential role in phototransduction. $\mathrm{Ca}$ appears to regulate the outer segment conductance indirectly by modulating the activity of the enzymes which control the level of cGMP within the cell (see, for example, Robinson et al., 1980; Torre et al., 1986; Hodgkin and Nunn, 1988; Koch and Stryer, 1988).

Received Dec. 18, 1989; revised Feb. 12, 1990; accepted Feb. 16, 1990.

We are cxtremely grateful to A. Eincrhand and J. Laucr for their cxcellent technical assistance. This research was supported in part by NIH Grants EY 01844 and EY 00331 and NSF Grant INT 84-04028 to G.L.F. and by a SFB 160 grant to W.H.S.

Correspondence should be addressed to Gordon L. Fain at the above address. Copyright (C) 1990 Society for Neuroscience $0270-6474 / 90 / 072238-12 \$ 03.00 / 0$
In this way, Ca seems to be primarily responsible for mediating the changes in sensitivity which occur during photoreceptor light adaptation (Matthews et al, 1988; Nakatani and Yau, 1988c; Fain et al., 1989).

In order to understand the role of $\mathrm{Ca}$ in the physiology of the rod, we have investigated changes in total $\mathrm{Ca}$ concentration in toad rod outer segments (Fain and Schröder, 1985, 1987) using a recently developed technique of microanaysis called laser micromass analysis (LAMMA). With this technique, it is possible to measure the total $\mathrm{Ca}$ content of a small (4-5 $\mu \mathrm{m}$ diametcr) region within a rod in the whole retina. One of the principal advantages of LAMMA is that it uses mass spectroscopy, so that it is possible to distinguish and separately measure signals from different $\mathrm{Ca}$ isotopes. In this way, it has been possible to study $\mathrm{Ca}$ movements into and out of rods and $\mathrm{Ca}$ pooling within the outer segment.

Results from our studies show that rods contain large amounts of $\mathrm{Ca}$ which are concentrated within the outer segments. The $\mathrm{Ca}$ is distributed within (at least) 2 pools: one which exchanges rapidly with $\mathrm{Ca}$ in the external medium and is apparently $\mathrm{Ca}$ within the cytosol, and another which exchanges very slowly and is probably $\mathrm{Ca}$ sequestered within the disks. Most of the total $\mathrm{Ca}$ in the rod is contained within the sequestered pool. In an earlier report (Schröder and Fain, 1984a), we showed that the $\mathrm{Ca}$ from this pool can be released by light. We now describe this release in more detail and show that it is part of a " $\mathrm{Ca}$ cycle" within the outer segment, which mirrors in some respects the visual cycle of the photopigment chromophore: Ca release in light is followed by $\mathrm{Ca}$ re-uptake in darkness, and the rate of re-uptake is facilitated by the presence of the pigment epithelium.

Some of these experiments have been previously presented at the annual meetings of the American Biophysical Society (Schröder and Fain, 1983) and the Association for Research in Vision and Ophthalmology (Schröder and Fain, 1987).

\section{Materials and Methods}

A detailed description of the methods used in this paper for isolation of the retina, processing of the tissue, and LAMMA analysis is given in Fain and Schröder (1985). In brief, dark-adapted toads (Bufo marinus) were pithed in darkness and their eyes removed using a stereo microscope equipped with 2 infrared converters (Find-R-Scope, F.J.W. Industries, Mount Prospect, IL). The anterior segment including the lens was removed, leaving an eyecup preparation. In most experiments, the eyecup was bisected, and the half containing the optic disk was discarded. The retina from the other half was then isolated free of pigment epithelium and sclera and mounted on a Millipore filter with the photoreceptors pointing upward. The retina isolated in this manner could be shown to have normal light responses, as monitored by the measurement of the electroretinogram. The retina together with its sup- 


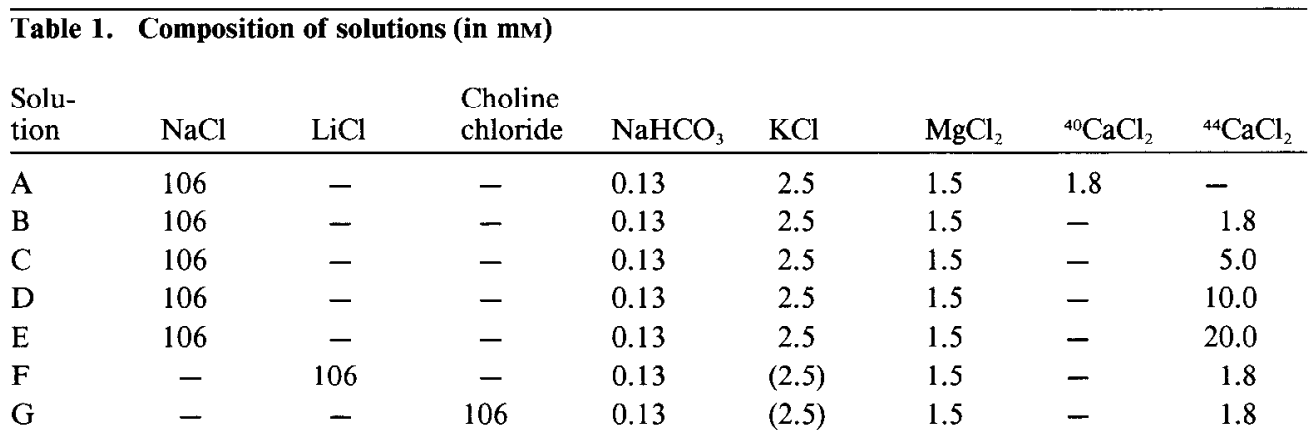

All solutions contained $5.6 \mathrm{~mm}$ glucose and $3.0 \mathrm{~mm}$ HEPES $\left(N\right.$-2-hydroxyethylpiperazine- $N^{\prime}$-2-ethanesulfonic acid). Solution $\mathrm{pH}$ was adjusted to $\mathrm{pH} 7.8$ with $\mathrm{NaOH}$ for solutions $\mathrm{A}-\mathrm{E}$. For $\mathrm{F}$ and $\mathrm{G}$, we used $\mathrm{KOH}$ and reduced the $\mathrm{KCl}$ accordingly, so that the total $\mathrm{K}^{+}$concentration remained $2.5 \mathrm{~mm}$. This is indicated by the parentheses around the $\mathrm{KCl}$ concentrations for these solutions.

porting filter was cut into 8 wedge-shaped samples (as for a pie), and one piece was immediately shock-frozen and processed as a control The other pieces were attached with insect pins to 30 -mm-diameter disks of dental wax, which were placed in 35-mm-diameter plastic Petri dishes containing oxygenated Ringer. Protocols for each of the experiments are given individually under Results.

In some experiments, in order to investigate the influence of the pigment epithelium on $\mathrm{Ca}$ movements in the photoreceptors, we did not isolate the retina. The whole eyecup was supported on a piece of filter paper and cut into 8 samples, each of which was then placed on moistened cotton cloth in a 35-mm-diameter Petri dish. The Petri dish was covered, and moistened $\mathrm{O}_{2}$ was introduced through a hole in the side. In order to process the retinas, we removed the pieces of evecup from the chamber, one immediately after the dissection as a control and the others after illumination as described in more detail under Results. The pieces of eyecup were then placed in oxygenated Ringer, and the retinas were isolated under the stereo microscope in darkness with infrared illumination and immediately shock-frozen. Isolation of the retina took $1-2 \mathrm{~min}$ for each piece.

The composition of the solutions used in these experiments is given in Table 1 . Solutions containing ${ }^{44} \mathrm{CaCl}_{2}$ (solutions $\mathrm{B}-\mathrm{G}$ ) were made by replacing the $\mathrm{CaCl}_{2}$ in the Ringer (which contained approximately $97 \%$ ${ }^{40} \mathrm{Ca}$ ) with $\mathrm{CaCl}_{2}$ containing approximately $96 \%{ }^{44} \mathrm{Ca}$. Stock solutions of ${ }^{44} \mathrm{CaCl}_{2}$ were prepared by dissolving ${ }^{44} \mathrm{CaCO}_{3}$ (Rohstoffeinfuhr, Dusseldorf, FRG) in $\mathrm{HCl}$. The $\mathrm{Ca}$ isotope composition of these solutions was measured and corrected for isotope impurity as described in Fain and Schröder (1987).

Photostimulator and light calibration. The photostimulator used in these experiments was similar to one previously described (Bastian and Fain, 1979) but contained only a single tungsten-halide source powered by a regulated DC supply. In most experiments, a narrow-bandwidth $(<10 \mathrm{~nm}$ ) interference filter with peak transmittance at $503 \mathrm{~nm}$ (Ditric Optics, Marlboro, MA) was placed in the beam. The intensity of the beam was attenuated with neutral glass absorption filters (Fish-Schurman Corp., New Rochelle, NY), which were calibrated on a Cary 17 spectrophotometer. Lenses and a circular aperture were used to project a field $50 \mathrm{~mm}$ in diameter onto a stage within a light-tight Faraday cage. This field was adjusted so that it was in focus at the plane of the retinas or eyecups. The light intensity within this field was uniform to within $\pm 10 \%$.

The absolute intensity of the $503 \mathrm{~nm}$ light without attenuation was set at the beginning of each experiment (at least $1 \mathrm{hr}$ after the photostimulator source had been turned on) to an intensity of $3.4 \times 10^{12}$ quanta $/ \mathrm{cm}^{2} / \mathrm{sec}$. The absolute intensity, once set, varied during the course of an experiment by less than $\pm 10 \%$. The calibration of the light stimulus was performed with a silicon photodiode (Pin-5, United Detector Technology, Santa Monica, CA) placed in the position normally occupied by the pieces of retina or eyecup. The photodiode was itself calibrated against a calibrated thermopile as in Bastian and Fain (1979). The photodiode we used in our measurements was the same as that used by Woodruff et al. (1982), and its calibration was confirmed by direct measurements of photopigment bleaching in a suspension of outer segments. The number of incident quanta falling on the retina was converted into rhodopsin molecules bleached per rod by assuming an effective collecting area of $29.5 \mu \mathrm{m}^{2}$ (Fain, 1976). In some experiments, we exposed the retina to an unattenuated white light, which we estimate from previous measurements (Fain, 1976) to have been approximately 20 times ( $1.3 \log$ units) brighter than the unattenuated $503 \mathrm{~nm}$ stimulus for the "red" rod photoreceptors.

Shock-freezing, tissue preparation, and microanalysis. As in previous experiments (Schröder and Fain, 1984a; Fain and Schröder, 1985, 1987), each of the samples of retina supported by the Millipore filters was shock-frozen by quick immersion in freezing Freon 22 (at $-150^{\circ} \mathrm{C}$ ) and was then transferred to cryosubstitution tubes $\left(a t-194^{\circ} \mathrm{C}\right)$. In all of the experiments in this paper, the retina was dehydrated by cryosubstitution in acetone- $\mathrm{OsO}_{4}$ and embedded in an Epon-Araldite mixture, as described in detail by Fain and Schröder (1985).

Calcium content was measured by LAMMA on a LAMMA-500 (Leybold-Hcracus, Cologne, FRG). A complete description of this instrument has been given previously (Wechsung et al., 1979; Vogt et al., 1981). Spectra were recorded with a transient recorder, transferred to a Hewlett Packard HP 1000 minicomputer (Hewlett Packard Inc., Palo Alto, CA) and stored on magnetic disks. A set of analytical programs first calibrated the positions of the peaks by comparison to previous spectra of known composition. Then, the $\mathrm{Ca}$ signals were calculated by integrating within the limits \pm 0.5 atomic mass unit ( $\mathrm{amu}$ ) of the peak for each isotope (see Fain and Schröder, 1985).

Electron microscopy. Electron micrographs were taken with a Phillips EM 400 electron microscope (Phillips, Einhoven, The Netherlands), fitted with twin lens and $\mathbf{a ~} \mathbf{L B}_{6}$ cathode. For the thick sections used in these experimennts, we used an acceleration voltage of $120 \mathrm{kV}$. Sections were mounted onto grids without any support film to reduce background for subscquent LAMMA analysis.

All measurements in this paper were made from "red" rods, which are maximally sensitive at $502 \mathrm{~nm}$ (Fain, 1976) and are referred to in the text simply as rods.

\section{Results}

When a dark-adapted rod was exposed to illumination, its $\mathrm{Ca}$ content decreased. This effect can be observed in the representative spectra given in Figure 1, part $A$ of which shows a LAMMA spectrum from a control piece of retina which was darkadapted and then shock-frozen immediately after the dissection. We show only that part of the spectrum for positively charged ions between $\mathrm{m} / \mathrm{e}=40$ and $\mathrm{m} / \mathrm{e}=44$ (see legend to Fig. 1). A more complete spectrum was given by Fain and Schröder (1985).

We have previously demonstrated that the large peak at $\mathrm{m} / \mathrm{e}$ $=40$ in dark-adapted rods consists almost cntircly of ${ }^{40} \mathrm{Ca}$ with little contamination from organic background (Fain and Schröder, 1985). This peak represents about $97 \%$ of the Ca normally present in the rod and corresponds to $4-5 \mathrm{~mm}$ total $\mathrm{Ca} /$ liter tissue volume. The much smaller peak at $\mathrm{m} / \mathrm{e}=44$, representing the small amount of ${ }^{44} \mathrm{Ca}$ normally present, is difficult to quantitate in single spectra, but the averaging of many spectra shows 


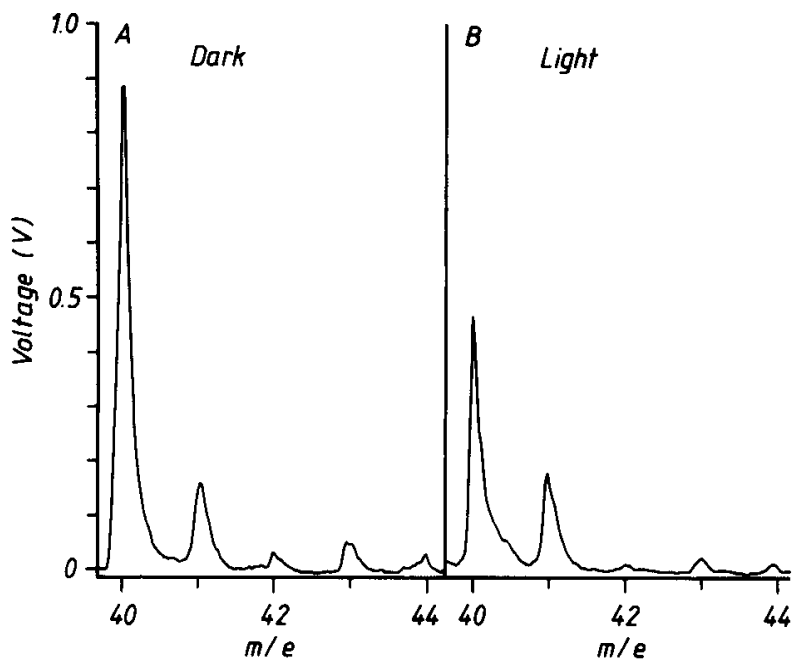

Figure 1. Spectra from LAMMA demonstrating light-induced decrease in total $\mathrm{Ca}$ content in outer segments of toad rods. Ordinate gives the voltage signal from the secondary electron multiplier tube of the $\mathrm{L} \Lambda \mathrm{MM} \Lambda$ after amplification. Note that the gain of amplification was made larger for the spectra in this figure than for those in Fain and Schröder $(1985,1987)$ in order to make the light-induced decrease in ${ }^{40} \mathrm{Ca}$ easier to observe. The abscissa gives mass in amu divided by charge. This is equivalent to mass in amu, since the microplasma produced by the high-energy laser of the LAMMA has been shown to produce almost exclusively singly charged particles (Wechsung et al., 1979; Vogt et al., 1981). Only that part of the mass spectrum for positively charged ions between $\mathrm{m} / \mathrm{e}=40$ and $\mathrm{m} / \mathrm{e}=44$ is shown (see Fain and Schröder, 1985). $A$, Spectrum of rod from control piece of dark-adapted retina, shock-frozen immediately after the dissection. $B$, Spectrum from rod from different piece from same retina which had been incubated in 1.8 $\mathrm{mM}{ }^{44} \mathrm{Ca}$ Ringer (solution B), illuminated continuously for $64 \mathrm{sec}$ with light bleaching $10^{6}$ rhodopsins $\left(\mathrm{Rh}^{*}\right) / \mathrm{rod} / \mathrm{sec}$, and immediately shockfrozen upon cessation of the illumination. Peaks at $\mathrm{m} / \mathrm{e}=40$ and $\mathrm{m} / \mathrm{c}$ $=44$ are for ${ }^{40} \mathrm{Ca}$ and ${ }^{44} \mathrm{Ca}$. Peaks at $\mathrm{m} / \mathrm{e}=41$ are for ${ }^{41} \mathrm{~K}$.

it to be $2-3 \%$ of the amplitude of the ${ }^{40} \mathrm{Ca}$ peak, in approximate agreement with its natural abundance (2.1\%; see Weast, 1970).

In Figure $1 B$, we show the effect of light on rod $\mathrm{Ca}$ content. In order to study light-induced changes in $\mathrm{Ca}$ flux in the photoreceptors, we placed pieces of retina in Ringer for which the ${ }^{40} \mathrm{CaCl}_{2}$ was replaced with ${ }^{44} \mathrm{CaCl}_{2}$ (solution $\mathrm{B}$, see Materials and Methods). In this way, it was possible to distinguish $\mathrm{Ca}$ releasc from the outer segment, measured as a decrease in ${ }^{40} \mathrm{Ca}$, from Ca uptake into the rod from the external solution, measured as an increase in ${ }^{44} \mathrm{Ca}$. Rates of $\mathrm{Ca}$ release and uptake do not necessarily measure true rates of $\mathrm{Ca}$ efflux and influx across the outer segment plasma membrane, since $\mathrm{Ca}$ in the rod is contained in at least 2 pools, and rates of $\mathrm{Ca}$ movement in the rod as a whole may be limited by movements to and from a more slowly exchanging compartment, for example, the disks (Fain and Schröder, 1987).

In Figure $1 B$, a piece of retina (from the same eye as for $A$ ) was incubated in ${ }^{44} \mathrm{Ca}$ Ringer and illuminated continuously for $64 \mathrm{sec}$ with a light bleaching $10^{6}$ rhodopsin molecules $\left(\mathrm{Rh}^{*}\right)$ / $\mathrm{rod} / \mathrm{sec}$. We calculate this illumination to have produced a total bleach of about $1 \%$ of the rhodopsin in the outer segment, assuming an outer segment envelope volume of $3 \mathrm{pl}$ (Fain and Schröder, 1987) and an outer segment rhodopsin concentration of $3 \mathrm{~mm}$ /liter total volume (Fein and Szuts, 1982). Light exposure caused a large decrease in the integral of the ${ }^{40} \mathrm{Ca}$ peak, corresponding to a release of approximately $50 \%$ of the total $\mathrm{Ca}$ content of the rod. The effect of light on $\mathrm{Ca}$ uptake was much smaller. In Figure $1 B$, no change in the amplitude of the ${ }^{44} \mathrm{Ca}$ peak could be detected. In other spectra taken under identical conditions, small increases in ${ }^{44} \mathrm{Ca}$ could be observed, as we shall describe in more detail below. In no case, however, did the incresase in ${ }^{44} \mathrm{Ca}$ compensate for the decrease in ${ }^{40} \mathrm{Ca}$.

\section{Time course of light-dependent Ca release}

We have previously shown (Schröder and Fain, 1984a) that when pieces of retina are incubated in ${ }^{44} \mathrm{Ca}$ Ringer and exposed for varying lengths of time to continuous light, the ${ }^{40} \mathrm{Ca}$ content of the outer segment decreases at a rate which increases with increasing light intensity. A small, though significant light-dependent release can be seen even at the relatively dim intensity of $68 \mathrm{Rh} * \mathrm{rod} / \mathrm{sec}$. At an intensity equivalent to the one used for Figure $1\left(10^{6} \mathrm{Rh}^{*} / \mathrm{rod} / \mathrm{sec}\right)$, the release occurs at a much faster rate (on the order of $10^{7}-10^{8} \mathrm{Ca} / \mathrm{rod} / \mathrm{sec}$ ). However, in our previous experiments, it was not possible for us to give an accurate description of Ca release in bright light, because of the slow time resolution of our measurements.

In order to obtain a more accurate estimate of the time course of $\mathrm{Ca}$ release, we measured $\mathrm{Ca}$ content in the outer segments of rods at a faster time resolution. These experiments were done in the following way. After shock-freezing one piece as a control, the other 7 pieces of a dark-adapted, isolated retina were placed in normal Ringer in darkness, whence 6 werc transferred onc at a time into $1.8 \mathrm{~mm}{ }^{44} \mathrm{Ca}$ Ringer and immediately exposed to a light intensity of $10^{6} \mathrm{Rh} * / \mathrm{rod} / \mathrm{sec}$ for $4,8,16,32,64$, or 128 sec. After each piece was illuminated, it was quickly shockfrozen. The time from cessation of illumination to the placing of the retina in freezing Freon 22 was 3-4 sec. After these 6 pieces were processed, the seventh piece (still in normal Ringer in darkness) was shock-frozen as a control.

The results of these experiments are given in Figure $2 A$. The filled circle and square at $t=128 \mathrm{sec}$ give the ${ }^{40} \mathrm{Ca}$ and ${ }^{44} \mathrm{Ca}$ content of the control pieces which were kept in darkness in normal Ringer and frozen after all of the illuminated pieces were processed. Although these data are plotted at $128 \mathrm{sec}$, the retinas from which they were obtained were actually frozen approximately $10 \mathrm{~min}$ after freezing the pieces used to obtain the filled circle and square plotted at $t=0$. Comparison of these 2 controls shows that thcre was little change in $\mathrm{Ca}$ content for the retinas in darkness during the time it took to do these experiments. This is consistent with the slow time courses of $\mathrm{Ca}$ influx and efflux for rods kept in darkness at the normal extracellular $\mathrm{Ca}$ concentration (Fain and Schröder, 1985).

The decrease in ${ }^{40} \mathrm{Ca}$ in the light-exposed pieces occurred sigmoidally with a brief delay. Very little release took place within the first $4 \mathrm{sec}$ of light exposure. The rate of ${ }^{40} \mathrm{Ca}$ release then increased to a maximum value between $t=8$ and $16 \mathrm{sec}$, which we estimate from the slope of the curve between these 2 data points to be approximately $2.5 \%$ of the total ${ }^{40} \mathrm{Ca}$ released/ $\mathrm{rod} / \mathrm{sec}$. Assuming an outer segment ${ }^{40} \mathrm{Ca}$ content of $4.5 \mathrm{mmol} /$ liter tissue volume and an outer segment envelope volume of 3 $\mathrm{pl}$, we calculate this maximum release rate to be equivalent to $2.0 \times 10^{8} \mathrm{Ca} / \mathrm{rod} / \mathrm{sec}$.

After $t=16 \mathrm{sec}$, the rate of release progressively declined, and from $t=64 \mathrm{sec}$ onward, little further release appeared to occur even though the total ${ }^{40} \mathrm{Ca}$ content of the outer segment had declined only to about $50 \%$ of its dark-adapted value. This finding is in agreement with our previous measurements, which show that even after $60 \mathrm{~min}$ of bright illumination, one-third 
to one-half of the ${ }^{40} \mathrm{Ca}$ remains within the outer segment (Schröder and Fain, 1984a).

In addition to the light-induced decrease in ${ }^{40} \mathrm{Ca}$, there appeared to be a small increase in ${ }^{44} \mathrm{Ca}$. All of the mean ${ }^{44} \mathrm{Ca}$ values of the illuminated samples were larger than either of the darkadapted controls or than the ${ }^{44} \mathrm{Ca}$ values we previously measured from rods incubated over a similar time course in $1.8 \mathrm{~mm}{ }^{44} \mathrm{Ca}$ Ringer (figure 6 of Fain and Schröder, 1985). A small, apparently light-induced uptake of ${ }^{44} \mathrm{Ca}$ after brief exposures to bright illumination can also be observed in Figures $4 B$ and 7 below, as well as in some of our previous measurements (e.g., open diamond at $t=1 \mathrm{~min}$ in figure 4 of Schröder and Fain, 1984a). This uptake of ${ }^{44} \mathrm{Ca}$ may have occurred at least in part as the result of the ${ }^{40} \mathrm{Ca}$ release, since some ${ }^{44} \mathrm{Ca}$ may have entered the rod as the ${ }^{40} \mathrm{Ca}$ exited via $\mathrm{Ca} / \mathrm{Ca}$ exchange (Schnetkamp, 1986; Fain and Schröder, 1987).

\section{Ca release in the eyecup}

The expcriments in Figures 1 and $2 A$ were done on retinas isolated from the pigment epithelium and perfused with artificial Ringer. In order to show that the time course and total amount of light-induced $\mathrm{Ca}$ release were not a peculiarity of this preparation, we examined the $\mathrm{Ca}$ content of photoreceptors illuminated under more physiological conditions. In Figure $2 B$, we show the results of experiments similar to those of Figure $2 A$ but performed on pieces of eyecup. Eight pieces from one eye or from both eyes of the same animal were collected in a closed chamber and oxygenated in darkness (see Materials and Methods). At the beginning of the experiment, one piece was removed, and the retina, isolated in the normal way in Ringer solution, was shock-frozen as a control. The other pieces were then placed one by one in a second chamber on the stage of the photostimulator. As in Figure $2 A$, the pieces were individually stimulated with light at an intensity of $10^{6} \mathrm{Rh}^{*} / \mathrm{rod} / \mathrm{sec}$ for 4 , $8,16,32,64$, or $128 \mathrm{sec}$. The retina from each piece was then isolated and shock-frozen. Finally, at the end of the experiment, the last piece was removed from darkness and its retina isolated and shock-frozen, as a control.

The circles in Figure $2 B$ give the ${ }^{40} \mathrm{Ca}$ content of the rod outer segments from these retinas. Since the eyecups were not incubated in ${ }^{44} \mathrm{Ca}$ Ringer, the normalized ${ }^{40} \mathrm{Ca}$ content reflects all the $\mathrm{Ca}$ present within the outer segments, including not only the $\mathrm{Ca}$ remaining after light-induced release but also any $\mathrm{Ca}$ taken up by the rods. These data can be compared with those from isolated retina simply by summing the values of the ${ }^{40} \mathrm{Ca}$ and ${ }^{44} \mathrm{Ca}$ measurements in Figure $2 A$ and normalizing to the total $\mathrm{Ca}$ in control retinas. The mean values of total $\mathrm{Ca}$ from isolated retinas are given as the triangles in Figure $2 B$ and are nearly superimposable onto the data from eyecups. Both sets of data show an initial delay in the decrease of the Ca content and a maximum rate of $\mathrm{Ca}$ efflux of the order of $2 \times 10^{8} \mathrm{Ca} / \mathrm{rod} /$ sec.

One complication of the data in Figure 2 is that, for the experiments with isolated retinas, the freezing of the retina occurred approximately 3-4 sec after the extinction of the light stimulus. For the eyecups, on the other hand, the freezing of the retina took place approximately 1-2 min after the light went off, since it was necessary to isolate the retina from each piece of eyecup before shock-freezing in order to produce satisfactory preservation of the tissue. This relatively long time between the end of the light stimulation and freezing appeared, however, not to have any significant influence on the time course of $\mathrm{Ca}$
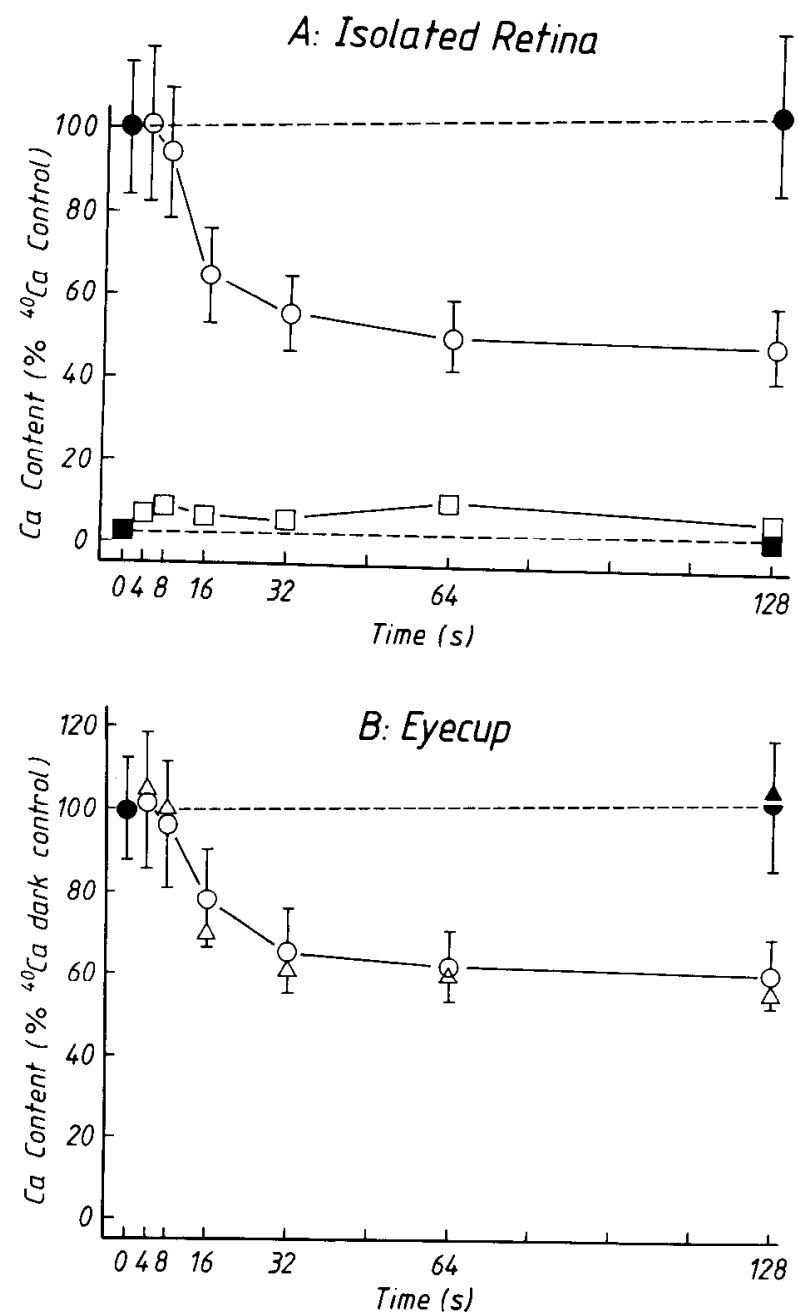

Figure 2. Time course of change in Ca content for short-duration exposures of bright light. For protocol for experiments, see text. Each data point gives mean of 10 outer segments each from 3-5 retinas. Error bars give $1 \mathrm{SD}$. All data are plotted as a percentage of the ${ }^{40} \mathrm{Ca}$ content of control pieces at $t=0$. Lines were drawn to connect points and are not meant to signify calculated curves. $A$, Isolated retinas. Closed circle and square at $t=0$ give ${ }^{40} \mathrm{Ca}$ and ${ }^{44} \mathrm{Ca}$ content from control pieces of retina, frozen immediately after the dissection. Closed circle and square at $t=128 \mathrm{sec}$ give ${ }^{40} \mathrm{Ca}$ and ${ }^{44} \mathrm{Ca}$ content from pieces kept in normal Ringer in darkness and frozen after all the light-stimulated pieces were processed. Open circles and squares give ${ }^{40} \mathrm{Ca}$ and ${ }^{44} \mathrm{Ca}$ content of pieces of retina incubated in $1.8 \mathrm{~mm}^{44} \mathrm{Ca}$ Ringer (solution $\mathrm{B}$ ) and exposed to light at an intensity of $10^{6} \mathrm{Rh}^{*} / \mathrm{rod} / \mathrm{sec}$ for the duration given on the abscissa. No error bars are given for ${ }^{44} \mathrm{Ca}$ data since the SDs were smaller than the symbols. $B, C$ a release in the eyecup. Closed circle at $t=0$ gives the mean ${ }^{40} \mathrm{Ca}$ content of controls frozen immediately after the dissection. Open circles give the mean ${ }^{4 \circ} \mathrm{Ca}$ content of rod outer segments in pieces exposed to a light of intensity $10^{6} \mathrm{Rh}^{*} / \mathrm{rod} / \mathrm{sec}$ for the durations indicated on abscissa. Closed circle at $t=128 \mathrm{sec}$ gives the mean ${ }^{40} \mathrm{Ca}$ content of pieces frozen after all of the light-exposed retinas were processed. Triangles give the Ca content of outer segments from Figure $3 \mathrm{~A}$, calculated from the sum of the mean ${ }^{40} \mathrm{Ca}$ and ${ }^{44} \mathrm{Ca}$ values, normalized to the sum of these values in the dark-adapted control pieces (see text).

release. We demonstrated this by illuminating an isolated retina in $1.8 \mathrm{~mm}{ }^{44} \mathrm{Ca}$ Ringer for $8 \mathrm{sec}$ with a light of $10^{6} \mathrm{Rh} / \mathrm{rod} / \mathrm{sec}$ and then varying the delay between the cessation of the light and the freezing of the retina. No significant change in ${ }^{40} \mathrm{Ca}$ content could be detected as a function of this delay interval, for delays as short as we could manage (3-4 sec) up to $2 \mathrm{~min}$. 

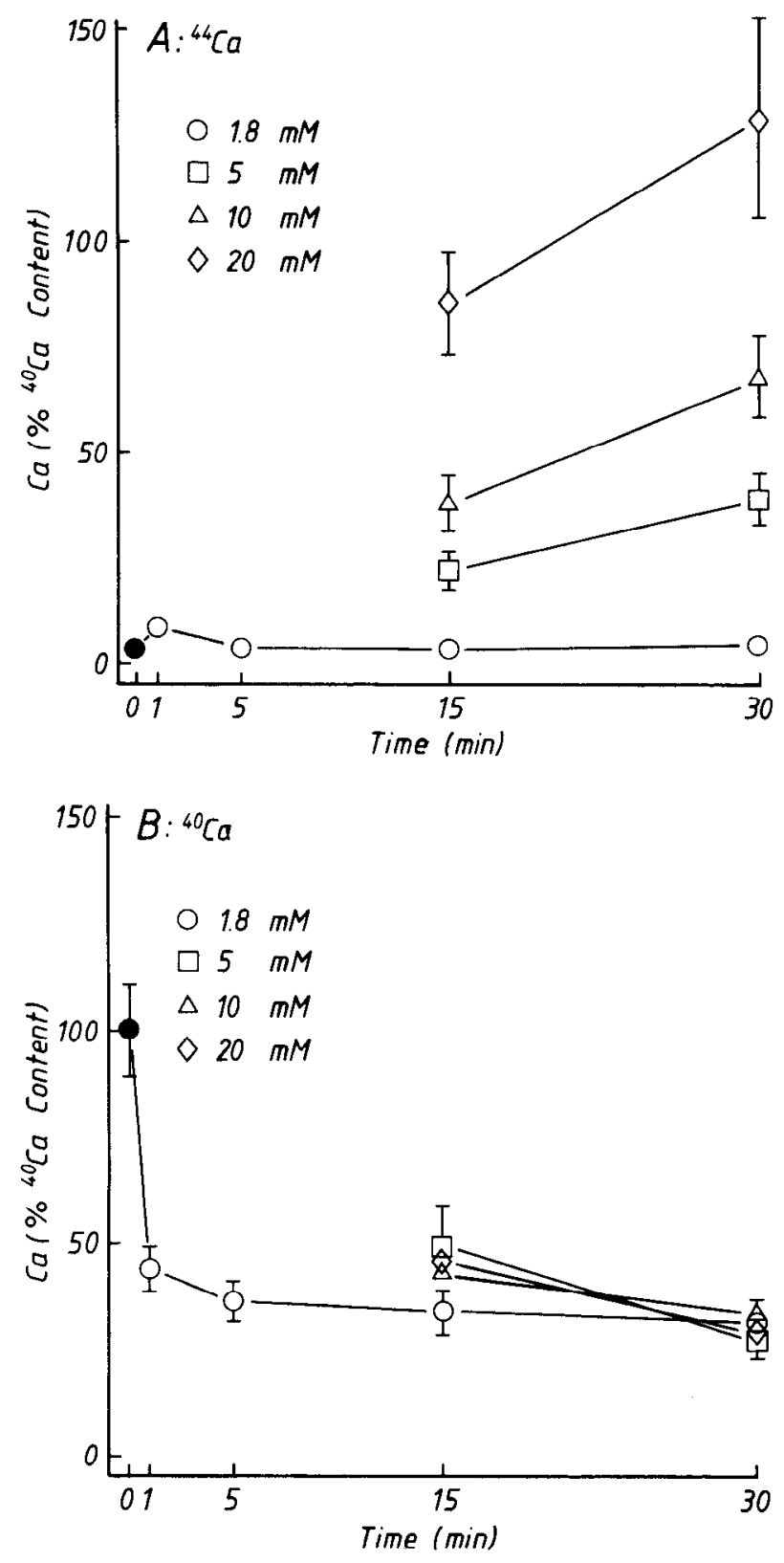

Figure 3. Time course of change of Ca content of rod outer segments incubated in high-Ca solutions in the presence of continuous illumination of intensity $10^{6} \mathrm{Rh}^{*} / \mathrm{rod} / \mathrm{sec}$. Data points give means and error bars, $1 \mathrm{SD}$ for ${ }^{44} \mathrm{Ca}(A)$ or ${ }^{40} \mathrm{Ca}(B)$ content, taken from 10 outer segments each from 4-5 retinas and corrected for impurity of isotope composition as previously described (Fain and Schröder, 1987). Data are plotted as a percentage of the ${ }^{4 n} \mathrm{Ca}$ content of control picces, frozen immediately after the dissection. After freezing controls, 6 remaining pieces were placed temporarily in normal Ringer (solution A). Two pieces were then transferred into one of the wells of the chamber (see text), and the whole chamber was illuminated with a continuous light at an intensity of $10^{6}$ $\mathrm{Rh}^{*} / \mathrm{rod} / \mathrm{sec}$. One minute after turning on the light, 2 more pieces were transferred together into a second well, where they became immediately exposed to the light. After again waiting $1 \mathrm{~min}$, the last 2 pieces were transferred into the third well. We staggered the entry of the pieces into the wells in this way so that they could be removed from each of the solutions and shock-frozen after exactly 15 and $30 \mathrm{~min}$. The 3 wells contained Ringer with ${ }^{44} \mathrm{CaCl}_{2}$ at the following concentrations (in mM): 5 (solution $\mathrm{C}, \square$ ); 10 (solution $\mathrm{D}, \triangle$ ); and 20 (solution $\mathrm{E}, \diamond$ ). Open circles except for control values give the $\mathrm{Ca}$ content in $1.8 \mathrm{~mm}^{44} \mathrm{CaCl}_{2}$ and were taken from triangles in figure 4 of Schröder and Fain (1984a). Data in $A$ and $B$ were taken from the same spectra. Lines were drawn to connect points and are not meant to signify calculated curves. Data

\section{Ca exchange in the light: high-Ca solutions}

The experiments of Figures 1 and 2 show that in the presence of continuous light, large amounts of ${ }^{\circ} \mathrm{Ca}$ leave the rod. However, this exit of ${ }^{40} \mathrm{Ca}$ was not accompanied by a comparable uptake of ${ }^{44} \mathrm{Ca}$. The ratc of ${ }^{44} \mathrm{Ca}$ accumulation in light was not much different from that in darkness (Schröder and Fain, 1984a), suggesting that the rate of exchange of external $\mathrm{Ca}$ for $\mathrm{Ca}$ originally present within the rod is rather slow irrespective of the presence or absence of illumination.

In order to investigate the rate of $\mathrm{Ca}$ exchange in more detail, we exposed rods to high external Ca solutions. These experiments were identical in protocol to those we have previously published (see figure 2 of Fain and Schröder, 1987), except that instead of incubating the retinas in darkness, we exposed them to continuous bright light. As in previous experiments, a retina isolated from a dark-adapted animal was cut into 8 pieces, and 1 or 2 were immediately shock-frozen as controls. The other 6 were placed in an experimental chmber, which for these experiments consisted of a piece of Teflon $50 \mathrm{~mm}$ in diameter and $12 \mathrm{~mm}$ high, into which had been milled $317-\mathrm{mm}$-diameter wells. Each well contained a disk of dental wax, so that the retinas could be fixed to the chamber bottom with insect pins. A plastic ring was used to hold the dental wax in place to prevent it from floating up when the chamber was filled with solution. The wells contained approximately $1 \mathrm{ml} 5 \mathrm{mM}$ (solution C), 10 $\mathrm{mm}$ (solution D), or $20 \mathrm{~mm}$ (solution E) ${ }^{44} \mathrm{Ca}$ Ringer and were illuminated with a light of intensity $10^{6} \mathrm{Rh}^{*} / \mathrm{rod} / \mathrm{sec}$.

The results of these experiments are given in Figure 3. Large amounts of ${ }^{44} \mathrm{Ca}$ accumulated in the rods in high $-{ }^{44} \mathrm{Ca}$ solutions at a rate which increased with increasing ${ }^{44} \mathrm{Ca}$ concentration. The rates of ${ }^{44} \mathrm{Ca}$ accumulation, estimated from the data points at 15 and $30 \mathrm{~min}$, were as follows: $5 \mathrm{mM}, 1.5 \times 10^{6} \mathrm{Ca} / \mathrm{rod} /$ sec; $10 \mathrm{~mm}, 2.7 \times 10^{6} \mathrm{Ca} / \mathrm{rod} / \mathrm{sec}$; and $20 \mathrm{~mm}, 4.0 \times 10^{6} \mathrm{Ca} /$ $\mathrm{rod} / \mathrm{sec}$. The experiments in Figure 3 can be directly compared to our previous results from rods incubated in these same high${ }^{44} \mathrm{Ca}$ solutions but in darkness (Fain and Schröder, 1987). This comparison shows that the rates of ${ }^{44} \mathrm{Ca}$ accumulation are somewhat smaller (by as much as a factor of 2) in continuous light than in darkness at the same Ca concentrations (see table 3 of Fain and Schröder, 1987).

In Figure $3 B$, we show the changes in ${ }^{40} \mathrm{Ca}$ content. The circles, giving the ${ }^{40} \mathrm{Ca}$ content in Ringer containing the normal $\mathrm{Ca}$ concentration, were taken directly from the triangles in figure 4 of Schröder and Fain (1984a). They show that the ${ }^{40} \mathrm{Ca}$ is reduced to between one-half and one-third of that of control pieces frozen in darkness. This represents the light-induced release of ${ }^{40} \mathrm{Ca}$ we have previously described (see Fig. 2). Other symbols give the results in high-Ca solutions, which are not significantly different at 15 and $30 \mathrm{~min}$ either from the data in $1.8 \mathrm{mM}{ }^{44} \mathrm{Ca}$ or from one another. These results indicate that in the light, the ${ }^{40} \mathrm{Ca}$ content is independent of the amount of ${ }^{44} \mathrm{Ca}$ accumulated within the rod, as we previously showed to be the case for rods in darkness (Fain and Schröder, 1987). Thus, the residual ${ }^{40} \mathrm{Ca}$ remaining after several minutes of exposure to bright light exchanges slowly, even when large amounts of ${ }^{44} \mathrm{Ca}$ enter from the external solution. in this figure arc directly comparable to figure 2 of Fain and Schröder
(1987), which shows ${ }^{44} \mathrm{Ca}$ uptake and ${ }^{40} \mathrm{Ca}$ relese in these same high${ }^{44} \mathrm{Ca}$ solutions in darkness. 
Dependence of $\mathrm{Ca}$ uptake and release on external $\mathrm{Na}$

The Ca released by light must exit from the rod across the plasma membrane. There is considerable evidence that the principal, if not the only, mechanism of $\mathrm{Ca}$ extrusion across the plasma membrane of rods is $\mathrm{Na} / \mathrm{Ca}$ (Schnetkamp, 1980, 1986; Yau and Nakatani, 1984b; Hodgkin et al., 1987; Lagnado et al., 1988) or $\mathrm{Na} / \mathrm{Ca}-\mathrm{K}$ (Cervetto et al., 1989) exchange. We therefore examined the effect on light-dependent $\mathrm{Ca}$ release and $\mathrm{Ca}$ uptake produced by substituting most of the $\mathrm{Na}$ in the Ringer with choline or $\mathrm{Li}$, both of which have been shown not to replace $\mathrm{Na}$ in Ca extrusion (Schnetkamp, 1980; Hodgkin and Nunn, 1987).

The protocol for these experiments was as follows. After shockfreezing the control, the other 7 pieces of a dark-adapted retina were transferred into 2 separate $35-\mathrm{mm}$ Petri dishes which both contained either solution $F$ or solution $G$, which were $1.8 \mathrm{~mm}$ ${ }^{44} \mathrm{Ca}$ Ringer solutions for which the $\mathrm{NaCl}$ was replaced either with $\mathrm{LiCl}$ or with choline chloride (see Table 1). One of the dishes (with 3 pieces) was left in darkness. The results of these experiments have already been given (see figure 8 of Fain and Schröder, 1985). The other dish (with the remaining 3-4 pieces) was illuminated with continuous light.

In Figure 4 we give ${ }^{40} \mathrm{Ca}$ release and ${ }^{44} \mathrm{Ca}$ uptake in choline chloride in the presence of light of an intensity of $8.1 \times 10^{3}$ $\mathrm{Rh}^{*} / \mathrm{rod} / \mathrm{sec}(A)$ and $10^{6} \mathrm{Rh}^{*} / \mathrm{rod} / \mathrm{sec}(B)$. In both $A$ and $B$ we also show for comparison release and uptake at these light intensities for $\mathrm{NaCl}$ Ringer (Schröder and Fain, 1984a). Dark controls for the mcasurcments in Figure $4 A$ have been previously published as figure $8 B$ of Fain and Schröder (1985), and the data in these 2 figures were obtained contemporaneously and from pieces of the same retinas.

The results in Figure 4 show that light-dependent ${ }^{40} \mathrm{Ca}$ efflux is much slower after the removal of most of the external $\mathrm{Na}$. Similar effects were seen upon replacing $\mathrm{Na}$ with $\mathrm{Li}$ (not shown). It is possible that the small release remaining after the removal of $\mathrm{Na}$ represents $\mathrm{Ca}$ transported out of the cell by a Na-independent mechanism (Matthews et al., 1988). Substitution of $\mathrm{Na}$ also produced a clear increase in ${ }^{44} \mathrm{Ca}$ uptake. A similar increase in ${ }^{44} \mathrm{Ca}$ accumulation was also seen in $\mathrm{Na}$-substituted Ringer in darkness (Fain and Schröder, 1985). Note again the anomalously high ${ }^{44} \mathrm{Ca}$ value in choline Ringer after $1 \mathrm{~min}$ in $10^{6} \mathrm{Rh}^{*} /$ $\mathrm{rod} / \mathrm{sec}$ (Fig. 4B).

\section{Light-dependent changes in ${ }^{40} \mathrm{C}$ a content in mitochondria}

Since bright light causes a large release of ${ }^{40} \mathrm{Ca}$, which, as we shall argue below (see p. 2247), probably occurs by the movement of $\mathrm{Ca}$ out of a sequestered pool within the disks into the cytoplasm, it scemed possible that the cytosolic frec-Ca concentration in the outer segment might at least transiently increase under these conditions. Our method is not suitable for measuring a change in free $\mathrm{Ca}$ in the outer segment due to release from a sequestered pool, since we measure total $\mathrm{Ca}$, that is, the sum of free and bound pools. We therefore investigated possible light-induced changes in the $\mathrm{Ca}$ content of the ellipsoid region of the rod, which in toad consists almost entirely of tightly packed mitochondria (W.H. Schröder, unpublished observations). These organelles in other systems have been shown to be able to take up $\mathrm{Ca}$ from the cytosol when the cellular freeCa concentration exceeds 1-2 $\mu \mathrm{M}$ (Tiffert and Brindley, 1981; Hirata and Koga, 1982; Burgess et al., 1983). We reasoned that an increase in cytosolic free $\mathrm{Ca}$ in the outer segment might cause
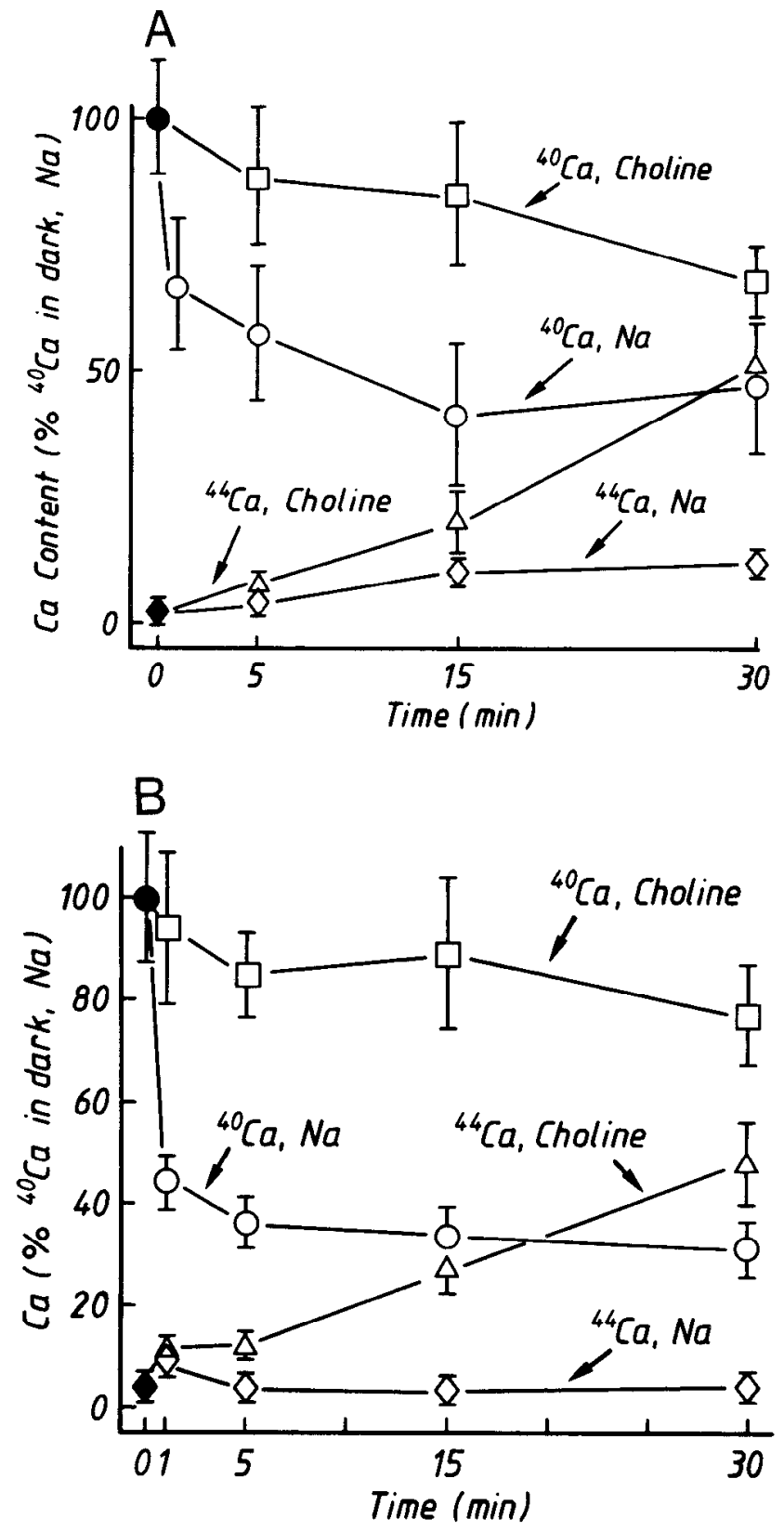

Figure 4. Ca release and uptake in Na-substituted Ringer in the presence of continuous light of intensity $8.1 \times 10^{3} \mathrm{Rh}^{*} / \mathrm{rod} / \mathrm{sec}(A)$ and $10^{6}$ $\mathrm{Rh}^{*} / \mathrm{rod} / \mathrm{sec}(B)$. Data points give means and error bars, $1 \mathrm{SD}$ from 10 outer segments each from 3-4 retinas, plotted as a percentage of the mean ${ }^{40} \mathrm{Ca}$ content of control pieces. Closed circle and diamond give ${ }^{40} \mathrm{Ca}$ and ${ }^{44} \mathrm{Ca}$, respectively, from controls frozen immediately after the dissection. All other data are from pieces exposed to continuous light. Retinas were incubated in $1.8 \mathrm{~mm}{ }^{44} \mathrm{Ca}$ Ringer (solution $\mathrm{G}$ ) for which $\mathrm{NaCl}$ was substituted with choline chloride $\left({ }^{40} \mathrm{Ca}, \square ;{ }^{44} \mathrm{Ca}, \triangle\right)$. In both $A$ and $B$, data from pieces in $1.8 \mathrm{mM}^{44} \mathrm{Ca}$ Ringer containing $\mathrm{Na}$ (solution B) taken from figure 4 of Schröder and Fain (1984a) are shown for comparison $\left({ }^{40} \mathrm{Ca}, \mathrm{O} ;{ }^{44} \mathrm{Ca}, \diamond\right)$. The controls produced for each series of experiments (in $\mathrm{Na}$ and choline in $A$ and $B$ ) were used to normalize the data in each of these series individually. Control data actually plotted in $A$ and $B$ show only measurements taken from $\mathrm{Na}$ incubations, but there was no significant difference in the mean ${ }^{40} \mathrm{Ca}$ content of the controls from the different sets of experiments. Lines were drawn to connect points and are not meant to signify caiculated curves. The measurements in $A$ were made from pieces of the same retinas used for figure $8 B$ of Fain and Schröder (1985), which shows Ca exchange in choline Ringer in darkness. 


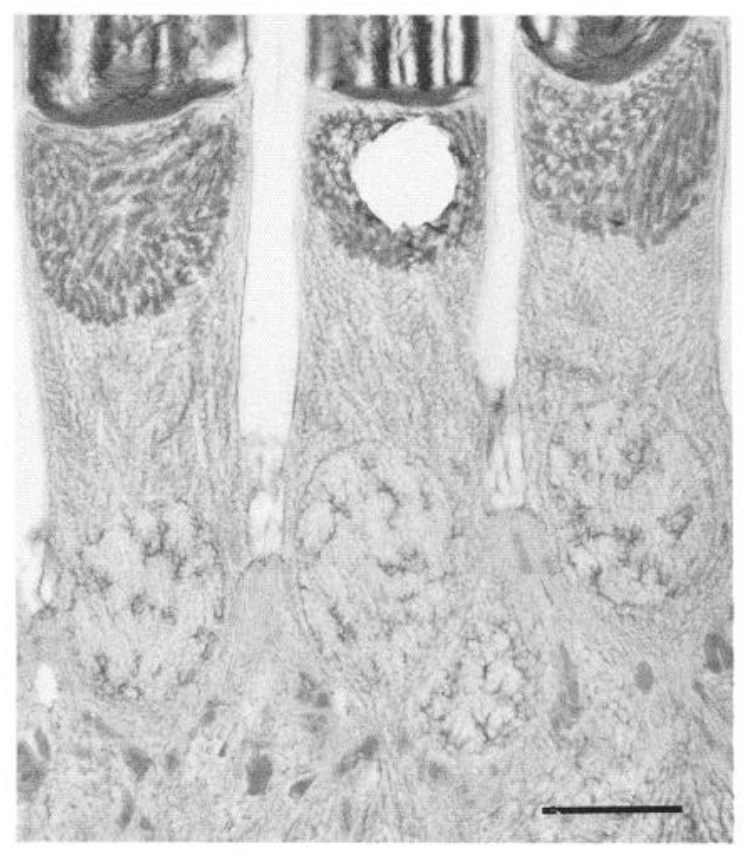

Figure 5. Low-power electron micrograph of rod inner segment after LAMMA analysis from ellipsoid. Section was $0.5 \mu \mathrm{m}$ thick, taken from dark-adapted retina incubated in darkness for $1 \mathrm{~min}$ in $1.8 \mathrm{~mm}{ }^{44} \mathrm{Ca}$ Ringer (solution B). Shock-frozen retina processed as described in Materials and Methods. Hole in ellipsoid was made by Nd:YAG laser of LAMMA-500. Scale bar, $5 \mu \mathrm{m}$.

an uptake of $\mathrm{Ca}$ into the mitochondria of the inner segment, and this would be detectable as an increase in total $\mathrm{Ca}$ in the ellipsoid body.

In order to make these measurements, we oriented the plane of section of the retina with some care, so that the rod inner segments were sufficiently well-aligned to make possible the placement of the LAMMA laser beam entirely within the ellipsoid. Placement of the laser was confirmed by examining sections at low power in the electron microscope after the $\mathrm{Ca}$ content had been analyzed (see Fig. 5). Measurements were made from retinas incubated in $1.8 \mathrm{~mm}{ }^{44} \mathrm{Ca}$ Ringer (solution B) at 2 light intensities: $8.1 \times 10^{3} \mathrm{Rh}^{*} / \mathrm{rod} / \mathrm{sec}$ (Fig. $6 \mathrm{~A}$, circles) and $10^{6} \mathrm{Rh}^{*} / \mathrm{rod} / \mathrm{sec}$ (Fig. $6 \mathrm{~B}$, circles). Since it seemed possible that the increase in free-Ca concentration might be larger in retinas for which $\mathrm{Ca}$ extrusion was inhibited by removing external $\mathrm{Na}$, we also measured at the same light intensities the $\mathrm{Ca}$ content of the ellipsoids of retinas incubated in choline chloride Ringer (solution G). These are shown in Figure 6, $A, B$, as the squares.

The results in Figure $6 A$ show that no significant change in ${ }^{40} \mathrm{Ca}$ content occurred in the mitochondria of the ellipsoid either in $\mathrm{NaCl}$ or in choline chloride Ringer at an intensity of $8.1 \times$ $10^{3} \mathrm{Rh}^{*} / \mathrm{rod} / \mathrm{sec}$. However, at $10^{6} \mathrm{Rh} * / \mathrm{rod} / \mathrm{sec}$ (Fig. $6 B$ ), a large transient increase in ${ }^{40} \mathrm{Ca}$ could be observed, from a dark-adapted level of approximately $7 \%$ of the outer segment ${ }^{40} \mathrm{Ca}$ concentration $(7 \%$ of $4.5 \mathrm{mmol} / \mathrm{liter}$ tissue volume, or about 300 $\mu \mathrm{mol} /$ liter $)$ up to a maximum level of about $30 \%(1.35 \mathrm{mmol} /$ liter tissue volume). There was no apparent difference in the magnitude or time course of the ${ }^{40} \mathrm{Ca}$ increase in $\mathrm{Na}$ (circles) and in choline (squares). The ellipsoid ${ }^{40} \mathrm{Ca}$ content was largest after $1 \mathrm{~min}$, at a time when most of the ${ }^{40} \mathrm{Ca}$ release from the rod outer segment was complete at this light intensity (see figures 2 and 4 of Schröder and Fain, 1984a). The ellipsoid ${ }^{40} \mathrm{Ca}$ content
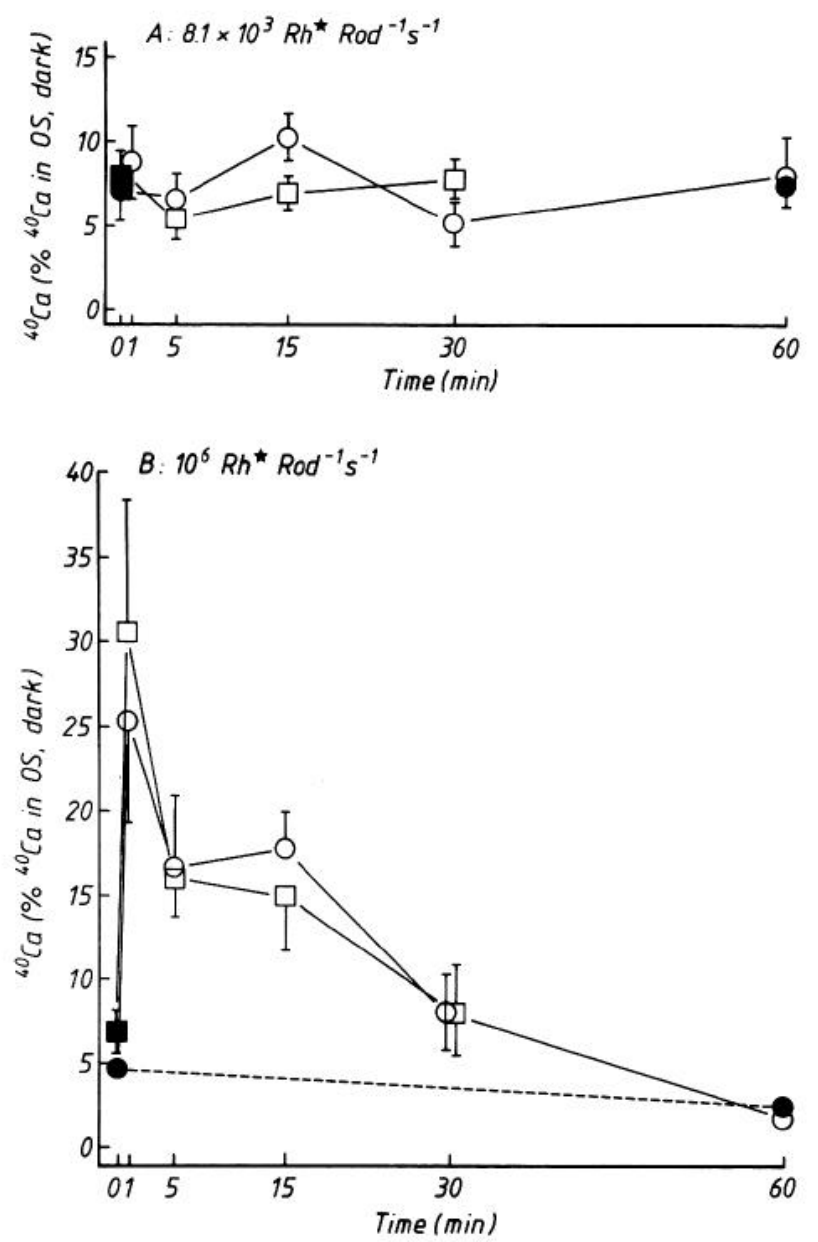

Figure 6. Light-dependent changes in calcium content in ellipsoid region of rod inner segment. Circles show measurements from retinas incubated in $1.8 \mathrm{mM}^{44} \mathrm{Ca}$ Ringer with $\mathrm{NaCl}$ (solution B) taken from the same experiments as used for figure 4 of Schröder and Fain (1984a). Squares show measurements from retinas incubated in $1.8 \mathrm{~mm}{ }^{44} \mathrm{Ca}$ Ringer with choline chloride (solution G), taken from the same experiments used for the squares in Figure 4. Filled circles and squares are measurements from control pieces frozen immediately after the dissection $(t=0)$ or after $1 \mathrm{hr}$ incubation in $1.8 \mathrm{~mm}^{44} \mathrm{Ca}$ Ringer in darkness $(t=60)$. Open symbols are from pieces of retina exposed to continuous light at an intensity of either $8.1 \times 10^{3} \mathrm{Rh}^{*} / \mathrm{rod} / \mathrm{sec}(A)$ or $10^{6} \mathrm{Rh}^{*} /$ $\mathrm{rod} / \mathrm{sec}(B)$. Data points give means from 17-42 $(A)$ or 25-61 $(B)$ rods and error bars, $1 \mathrm{SD}$. Data are plotted as a percentage of mean ${ }^{40} \mathrm{Ca}$ from control outer segments. Only ${ }^{40} \mathrm{Ca}$ content is shown, since ${ }^{40} \mathrm{Ca}$ in ellipsoid was always $<1 \%$ of control outer segment ${ }^{40} \mathrm{Ca}$ and was therefore too small to be measured accurately with the LAMMA-500. Lines were drawn to connect points and are not meant to signify calculated curves.

then gradually decayed back to its original dark-adapted level. From the relative volumes of the ellipsoid body and rod outer segment, we calculate that the $\mathrm{Ca}$ taken up by the mitochondria represents approximately $5 \%$ of the total ${ }^{40} \mathrm{Ca}$ released from the outer segment in the light (Schröder and Fain, 1984b).

\section{Reuptake of $\mathrm{Ca}$ by rods during dark adaptation: isolated retina}

Our experiments show that continuous illumination produces a release of as much as $50 \%$ of the $\mathrm{Ca}$ from the outer segment but has little effect on Ca re-uptake, so that the total Ca content of the rod decreases in the light (figures 2 and 4 of Schröder and Fain, 1984a). Since measurements from dark-adapted retinas 


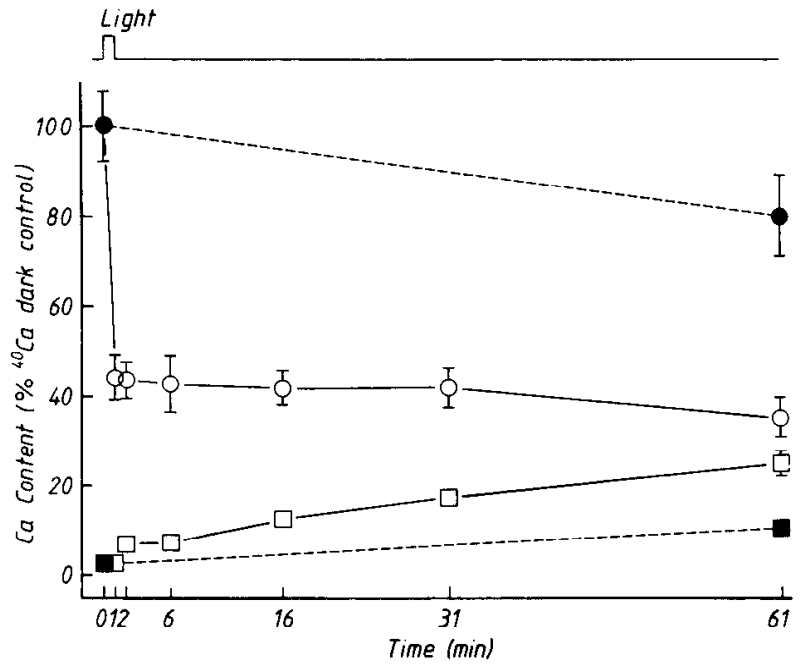

Figure 7. Ca uptake in darkness after illumination in isolated retina. Data points give means and error bars, 1 SD from 10 outer segments each from 4 dark-adapted retinas. Retinas were incubated in $1.8 \mathrm{~mm}$ ${ }^{14} \mathrm{Ca}$ Ringer (solution B). Circles give ${ }^{40} \mathrm{Ca}$ content and squares, ${ }^{44} \mathrm{Ca}$, plotted as a percentage of the mean ${ }^{40} \mathrm{Ca}$ content of control pieces, frozen immediately after the dissection. Closed symbols at $t=0 \mathrm{~min}$ give measurements from controls, and closed symbols at $t=61 \mathrm{~min}$ give measurements from pieces kept in darkness in $1.8 \mathrm{mM}{ }^{44} \mathrm{Ca}$ Ringer throughout the experiment. Open symbols are from pieces of retina exposed to light of intensity $10^{6} \mathrm{Rh}^{*} / \mathrm{rod} / \mathrm{sec}$ for $1 \mathrm{~min}$ and then placed in darkness and removed at times indicated on the abscissa. Timing of illumination is indicated by uppermost trace. Lines were drawn to connect points and are not meant to signify calculated curves.

(for example, control pieces frozen in darkness just after the dissection) uniformly gave an average Ca content about twice as large as from pieces of retina exposed to bright light, some mechanism must exist at least in the intact eye for replenishing the $\mathrm{Ca}$ after light exposure.

To test for such a mechanism, we investigated the rate of $\mathrm{Ca}$ uptake after brief illumination with bright light. After freezing one control piece from an isolated retina, we placed the 7 remaining pieces into ${ }^{44} \mathrm{Ca}$ Ringer (Table 1, solution B) in 2 Petri dishes, 6 in one and 1 in the other. The chamber containing the 6 pieces was illuminated with bright light for a fixed period of time. One piece was removed from this chamber immediately after illumination and processed in the usual way. The other 5 were removed at various times in darkness after the light exposure. The Petri dish containing the single piece in ${ }^{44} \mathrm{Ca}$ Ringer was left in darkness for the duration of the experiment, and the retinal piece was removed and frozen at the end, as a measure of changes in $\mathrm{Ca}$ content in the absence of illumination.

In Figure 7, we show Ca release and re-uptake following a 1 min exposure to a light bleaching $10^{6} \mathrm{Rh}^{*} / \mathrm{rod} / \mathrm{sec}$, which bleached about $1 \%$ of the pigment (see p. 2240). Exposure at this illumination reduced the ${ }^{40} \mathrm{Ca}$ content to about the same level as in previous experiments but had little effect on the ${ }^{44} \mathrm{Ca}$ content. During the $60 \mathrm{~min}$ in darkness after the light exposure, the ${ }^{40} \mathrm{Ca}$ showed a small decrease. The ${ }^{44} \mathrm{Ca}$ content, on the other hand, increased at a rate 2-3 times faster than that for rods in darkness without prior illumination or for rods in continuous light (Schröder and Fain, 1984a). Note that the rate of increase was also greater than that observed for the pieces of retina in the present experiments which were left in $1.8 \mathrm{~mm}{ }^{44} \mathrm{Ca}$ Ringer in continuous darkness (filled square at $t=61 \mathrm{~min}$ ).
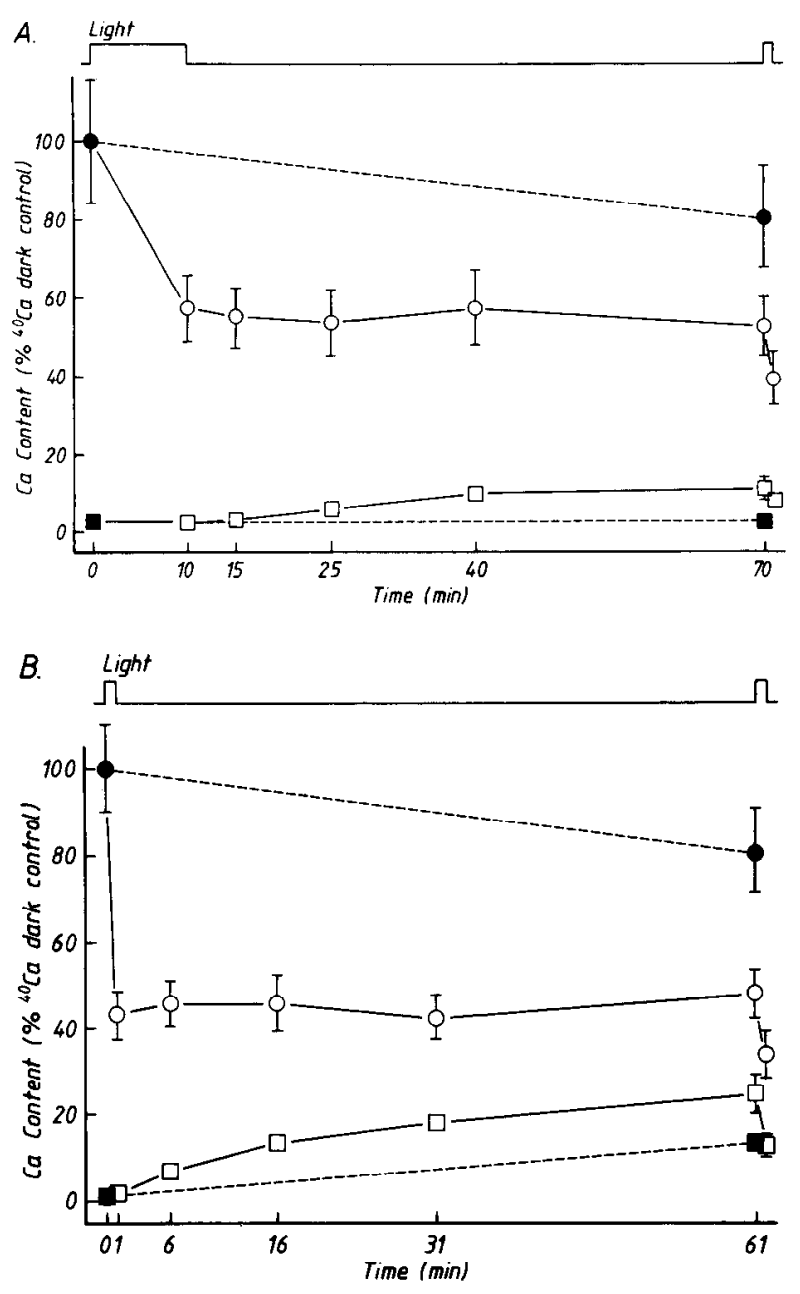

Figure 8. Ca uptake in darkness after illumination in isolated retina at 2 further intensities. Data points give means and error bars, $1 \mathrm{SD}$ from 10 outer segments each from 4-5 dark-adapted retinas. Retinas were incubated in $1.8 \mathrm{mM}^{44} \mathrm{Ca}$ Ringer (solution B). Circles give ${ }^{40} \mathrm{Ca}$ content and squares, ${ }^{44} \mathrm{Ca}$, plotted as a percentage of the mean ${ }^{40} \mathrm{Ca}$ content of control pieces, frozen immediately after the dissection. Closed symbols at $t=0 \mathrm{~min}$ give measurements from controls, and closed symbols at $t=70 \mathrm{~min}(A)$ or at $t=61 \mathrm{~min}(B)$ give measurements from pieces kept in darkness in $1.8 \mathrm{~mm}{ }^{44} \mathrm{Ca}$ Ringer throughout the experiment. Open symbols are from pieces of retina exposed to light of intensity $8.1 \times 10^{3} \mathrm{Rh}^{*} / \mathrm{rod} / \mathrm{sec}$ for $10 \mathrm{~min}(A)$ or to unattenuated white light for $1 \mathrm{~min}(B)$. Pieces were then placed in darkness and removed at times indicatcd on the abscissa. Onc picce was reilluminated for $1 \mathrm{~min}$ with an unattenuated white light. Timing of illumination is indicated by uppermost trace. Lines were drawn to connect points and are not meant to signify calculated curves.

The results of similar experiments at 2 further intensities are given in Figure 8. In $A$, the retinas were exposed for $10 \mathrm{~min}$ to a light bleaching $8.1 \times 10^{3} \mathrm{Rh}^{*} / \mathrm{rod} / \mathrm{sec}$, for a total bleach of about $0.1 \%$ (10-fold smaller than in Fig. 7$)$. In $B$, the retinas were illuminated with a 1 min exposure to an unattenuated white light, which we estimate to have bleached about $20 \%$ of the pigment (see Materials and Methods), or 20-fold more than in Figure 7 . In both cases, illumination produced a decrease in ${ }^{40} \mathrm{Ca}$ which was stable in darkness. The rate of ${ }^{44} \mathrm{Ca}$ uptake was larger in darkness after illumination than for the pieces maintained in $1.8 \mathrm{~mm}^{44} \mathrm{Ca}$ Ringer in continuous darkness, but this effect appears to have been smaller for the $0.1 \%$ bleach (Fig. $8 A$ ) than for the $1 \%$ (Fig. 7 ) or $20 \%$ bleaches (Fig. $8 B$ ). 

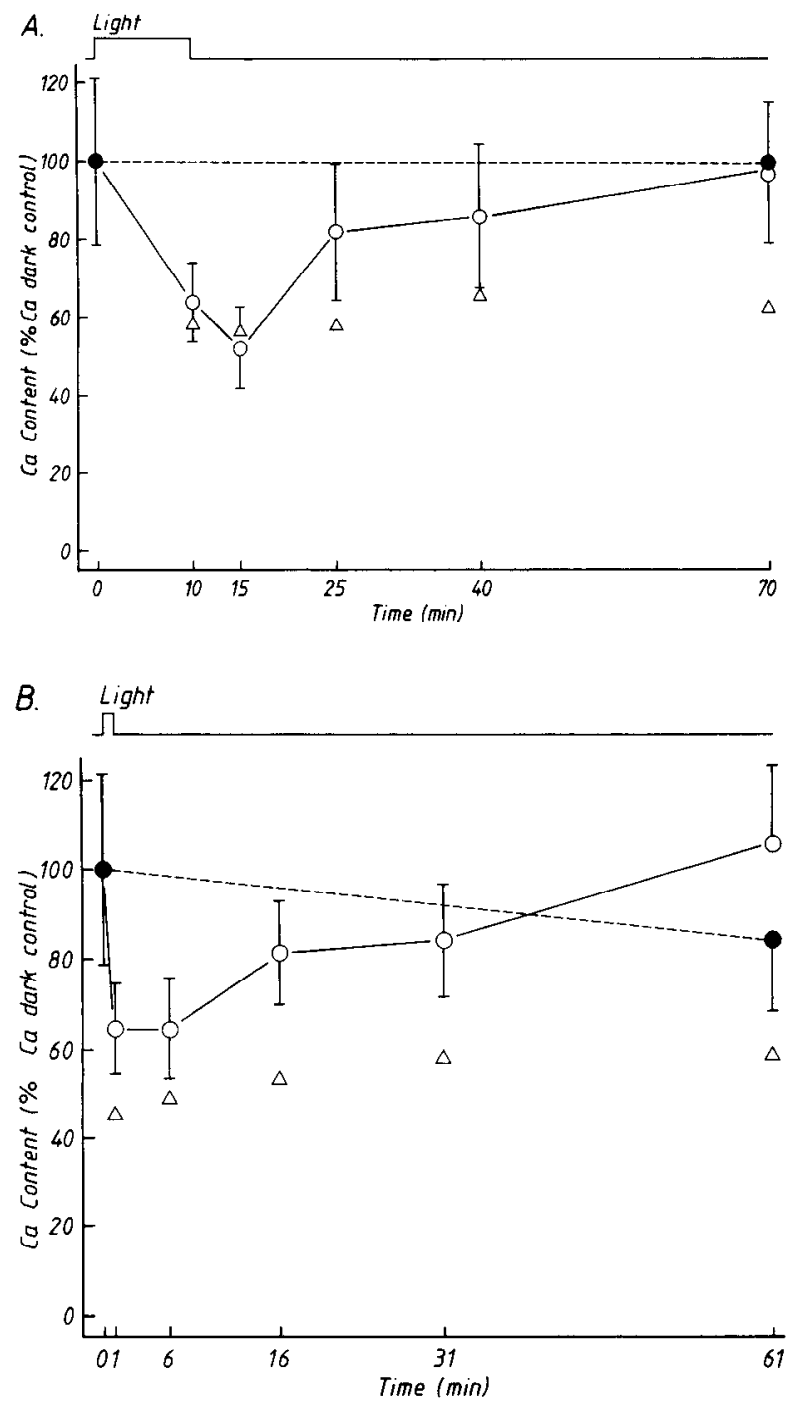

Figure 9. Ca uptake in darkness after illumination in eyecup. Circles give means and error bars, 1 SD from 10 outer segments each from 36 retinas. Closed circles at $t=0 \mathrm{~min}$ give measurements from control pieces, frozen in darkness immediately after the dissection. Closed circles at $t=70 \mathrm{~min}(A)$ or at $t=61 \mathrm{~min}(B)$ give measurements from pieces kept in darkness throughout the experiment. Open symbols are from pieces of retina exposed to light of intensity $8.1 \times 10^{3} \mathrm{Rh}^{*} / \mathrm{rod} / \mathrm{sec}$ for $10 \mathrm{~min}(A)$ or $10^{6} \mathrm{Rh}^{*} / \mathrm{rod} / \mathrm{sec}$ for $1 \mathrm{~min}(B)$. Pieces were then placed in darkness and removed at times indicated on the abscissa. Timing of illumination is indicated by uppermost trace. Triangles give the $\mathrm{Ca}$ content of outer segments from isolated retinas, which were exposed to the same light intensity for the same duration. They were calculated for $A$ from the data of Figure $8 A$, and for $B$ from the data of Figure 7 . Triangles give the sum of the mean ${ }^{40} \mathrm{Ca}$ and ${ }^{44} \mathrm{Ca}$ values, normalized to the sum of these values in dark-adapted control pieces. Lines were drawn to connect points and are not meant to signify calculated curves.

In both $A$ and $B$ of Figure 8, one of the pieces illuminated at the beginning of the experiment and kept in $1.8 \mathrm{mM}^{44} \mathrm{Ca}$ Ringer in darkness for $60 \mathrm{~min}$ was re-illuminated with a $1 \mathrm{~min}$ exposure to unattenuated white light. Re-illumination produced a decrease in the ${ }^{44} \mathrm{Ca}$ level, which is most apparent in Figure $1 B$ for the $20 \%$ bleach. Re-illumination also reduced the ${ }^{40} \mathrm{Ca}$ content. This is of some interest, since it suggests that $\mathrm{Ca}$ reentering the outer segment in darkness can exchange with the $\mathrm{Ca}$ remaining after bright light exposure. We shall return to this point in the Discussion.

\section{Re-uptake of $\mathrm{Ca}$ by rods in the eyecup}

The rate of Ca uptake in Figures 7 and 8 , though faster than in complete darkness or continuous light, seems still to be rather slow. Our data suggest that, in isolated retina, at least $2 \mathrm{hr}$ would be required for ${ }^{44} \mathrm{Ca}$ uptake to return the total $\mathrm{Ca}$ content of the outer segment to its dark-adapted value for the range of bleaches which we have investigated. It seemed to us possible that the rate of $\mathrm{Ca}$ re-uptake might be greater if the retinal pigment epithelium (RPE) were present. We tested this notion using a protocol similar to that for Figures 7 and 8 but with pieces of eyecup. We did not incubate the tissue in ${ }^{44} \mathrm{Ca}$ Ringer, since retinas from small pieces of eyecup incubated for long periods of time in Ringer often detached, and since we did not know the time course with which the $\mathrm{Ca}$ in the Ringer would exchange with the $\mathrm{Ca}$ in the interreceptor space. We therefore placed the pieces of eyecup in oxygenated chambers like those used for the experiments of Figure $2 B$ (see Materials and Methods).

Figure 9 gives the results of these experiments for a $10 \mathrm{~min}$ exposure to $8.1 \times 10^{3} \mathrm{Rh}^{*} / \mathrm{rod} / \mathrm{sec}$ (Fig. $9 \mathrm{~A}$ ) and $1 \mathrm{~min}$ exposure to $10^{6} \mathrm{Rh}^{*} / \mathrm{rod} / \mathrm{sec}$ (Fig. $9 B$ ). The normalized ${ }^{40} \mathrm{Ca}$ content of eyecups is plotted as the circles and is compared to the normalized sum of the ${ }^{40} \mathrm{Ca}$ and ${ }^{44} \mathrm{Ca}$ contents from isolated retinas (triangles), taken from the data in Figures 7 and $8 A$. The SDs for the eyecup measurements in Figure 9 are large, perhaps because the necessity of isolating the retina individually from each piece of eyecup increased the variability of our measurements. Despite this difficulty, the results in Figure 9 clcarly indicate that $\mathrm{Ca}$ is taken up more quickly in eyecup than in isolated retina and that total $\mathrm{Ca}$ returns to its dark-adapted level no more than $60 \mathrm{~min}$ after illumination for the range of intensities we examined.

\section{Discussion}

In Figure 10, we summarize the mechanisms which we believe to be responsible for $\mathrm{Ca}$ fluxes into and out of the cytoplasm and disks of a vertebrate rod. In darkness (Fig. 10 A), Ca enters the rod through light-dependent channels (Yau and Nakatani, 1984a; Hodgkin et al., 1985) and produces a continuous influx (in toad) of about $10^{7} \mathrm{Ca} / \mathrm{rod} / \mathrm{sec}$. This influx is balanced by a comparable efflux by way of $\mathrm{Na} / \mathrm{Ca}$ or $\mathrm{Na} / \mathrm{Ca}-\mathrm{K}$ exchange (Schnetkamp, 1980, 1986; Yau and Nakatani, 1984b; Hodgkin et al., 1987; Cervetto et al., 1989). The Ca moving into and out of the rod across the plasma membranc exchanges rapidly with the $\mathrm{Ca}$ free or loosely bound within the cytoplasm $\left(\mathrm{Ca}_{\mathrm{in}}\right)$ but slowly with the great majority of $\mathrm{Ca}$ within the rod, which, as we have previously argued (Fain and Schröder, 1985), is probably sequestered within the disks $\left(\mathrm{Ca}_{\text {disk }}\right)$.

Illumination has 2 effects on the $\mathrm{Ca}$ economy of a rod. In the first place, light decreases the influx of $\mathrm{Ca}$ through the lightdependent channels. As others have previously argued (Yau and Nakatani, 1985; Nakatani and Yau, 1988a), this has the effect also of reducing efflux via $\mathrm{Na} / \mathrm{Ca}$ or $\mathrm{Na} / \mathrm{Ca}-\mathrm{K}$ exchange and of decreasing the intracellular free $\mathrm{Ca}$ concentration. In the second place, light causes a decrease in the ${ }^{40} \mathrm{Ca}$ content of the rod (Figs. $1-4,6-9$ ). Some of this ${ }^{40} \mathrm{Ca}$ may come from the pool of free or loosely bound $\mathrm{Ca}$ within the cytoplasm. However, in bright light the decrease of ${ }^{4} \mathrm{Ca}$ is so large that most of it must come from the sequestered pool within the disks.

If light produces a release of $\mathrm{Ca}$ from the disks into the cytoplasm, this release should have some effect upon the cytosolic free $\mathrm{Ca}$ concentration in the outer segment. In dim light this 
A. DARK
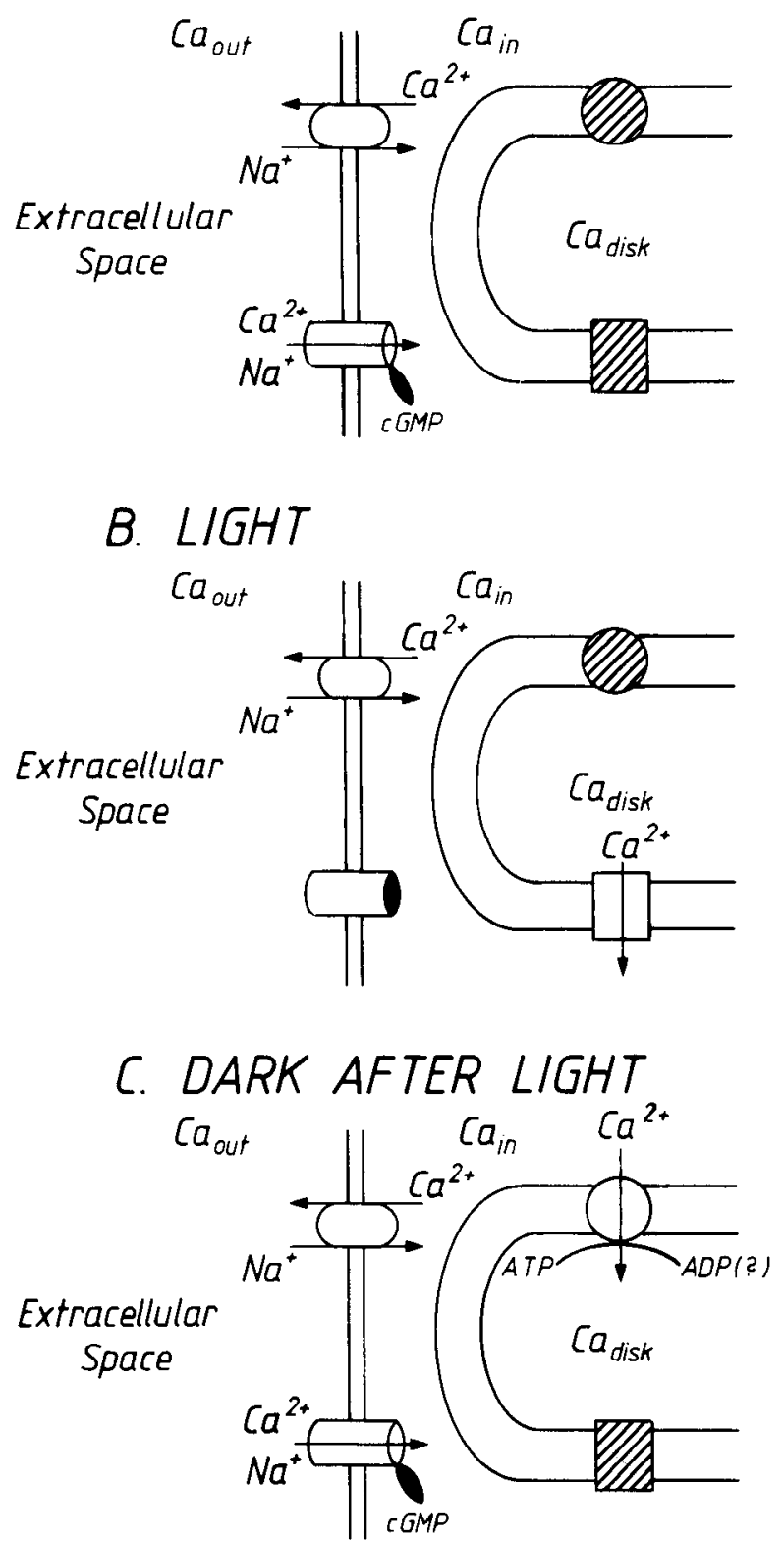

Figure 10. Summary diagram illustrating $\mathrm{Ca}$ fluxes across rod plasma membrane and disks in darkness $(A)$, in bright light $(B)$, and in darkness after light exposure $(C)$. See text.

effect is likely to be small, since our measurements show that the rate of ${ }^{40} \mathrm{Ca}$ decrease is small $\left(10^{6} \mathrm{Ca} / \mathrm{rod} / \mathrm{sec}\right)$ by comparison to the expected decrease in influx through the light-dependent channels $\left(10^{7} \mathrm{Ca} / \mathrm{rod} / \mathrm{sec}\right.$ - see Yau and Nakatani, 1984a; Hodgkin et al., 1985). In bright light, on the other hand, the rate of ${ }^{40} \mathrm{Ca}$ decrease after a few seconds delay reaches a maximum value $\left(1-2 \times 10^{8} \mathrm{Ca} / \mathrm{rod} / \mathrm{sec}\right)$ much greater than the decrease in influx through the channels in the plasma membrane. The cytosolic free $\mathrm{Ca}$ concentration might therefore be expected to increase at least transiently. Such an increase would explain our observation of a transient rise in total $\mathrm{Ca}$ in the mitochondriarich ellipsoid body of the rod (Fig. 6B).

We believe that at least part of the light-dependent ${ }^{40} \mathrm{Ca}$ release we have measured occurs as the result of a change in the permeability or transport of $\mathrm{Ca}$ across the disk membrane (Fig.
$10 B)$. Our experiments may give some clue as to the mechanism of this release. They show that, in continuous illumination, $\mathrm{Ca}$ is able to leave the rod at least initially at rates of up to $1-2 \times$ $10^{8} \mathrm{Ca} / \mathrm{rod} / \mathrm{sec}$, but ${ }^{44} \mathrm{Ca}$ is able to reenter in exchange for ${ }^{40} \mathrm{Ca}$ at a rate not significantly greater than that in darkness (1-3 $\times$ $\left.10^{5} \mathrm{Ca} / \mathrm{rod} / \mathrm{sec}\right)$. They also show that the residual ${ }^{40} \mathrm{Ca}$ left after several minutes exposure to continuous bright light exchanges slowly even under conditions in which large amounts of ${ }^{44} \mathrm{Ca}$ enter the rod from the external medium (Fig. 3). If light were to open a channel across the disk, movement of $\mathrm{Ca}$ through this channel must rectify, so that Ca exits from the disk much faster than it enters. This could occur either because the conductance of the channel itself rectifies or because the free $\mathrm{Ca}$ concentration in the cytosol is buffered to a much lower value than in the disk, even when the outer segment is loaded with Ca from the external solution. Alternatively, light may activate some form of Ca transporter.

Most of the ${ }^{40} \mathrm{Ca}$ released in the light appears to leave the outer segment by means of a Na-dependent process (Fig. 4), probably $\mathrm{Na} / \mathrm{Ca}$ or $\mathrm{Na} / \mathrm{Ca}-\mathrm{K}$ exchange. It is therefore surprising that a large light-dependent $\mathrm{Ca}$ efflux has not previously been detected from measurements of extracellular Ca concentration (Gold and Korenbrot, 1980; Yoshikami et al., 1980; Gold, 1986; Miller and Korenbrot, 1987). This discrepancy may be explained by differences in experimental protocols. It is important to realize that the large ${ }^{40} \mathrm{Ca}$ release we have observed was seen only transiently and only with bright light stimulation, and the ability of rods to release such large amounts of $\mathrm{Ca}$ recovered slowly after an initial illumination (Figs. 7-9). It seems possible that the conditions of previous experiments were not similar enough to those we have used to permit the detection of the $\mathrm{Ca}$ release we have observed.

It is also surprising that a large $\mathrm{Ca}$ cfflux has not becn detected from measurements of $\mathrm{Na} / \mathrm{Ca}$ or $\mathrm{Na} / \mathrm{Ca}-\mathrm{K}$ exchange currents. If the stoichiometry of $\mathrm{Ca}$ transport can be assumed to be 3 $\mathrm{Na}^{+}: 1 \mathrm{Ca}^{2+}$ (Yau and Nakatani, 1984b; Hodgkin et al., 1987; Lagnado et al., 1988; Nakatani and Yau, 1988a) or $4 \mathrm{Na}^{+}: 1 \mathrm{Ca}^{2+}$ $+1 \mathrm{~K}^{+}$(Cervetto et al., 1989), our experiments predict that ${ }^{40} \mathrm{Ca}$ release from the outer segment with the time course shown in Figure 2 at a maximal rate of $1-2 \times 10^{8} \mathrm{Ca} / \mathrm{rod} / \mathrm{sec}$ should produce an exchange current, with a time course given by the derivative of the curve in Figure 2 and with a maximal amplitude of 16-32 pA. Although exchange currents of this magnitude and time course have not previously been recorded from photoreceptors at a physiological Ca concentration (Nakatani and Yau, 1988a), such a current would only be recorded from a thoroughly dark-adapted rod isolated in such a way as to maintain the full Ca complement of its outer segment (Nicol et al., 1987). Furthermore, an exchange current of this magnitude would only be elicited by bright light and only for the first exposure to illumination.

\section{Ca re-uptake after illumination}

Although uptake of $\mathrm{Ca}$ is slow in dark-adapted rods and in rods exposed to continuous illumination, it is enhanced in darkness after the cessation of bright light (Figs. 7-9). We speculate (Fig. $10 C$ ) that the turning off of bright light stimulates the transport of $\mathrm{Ca}$ back into the disk. There is evidence for ATP-dependent Ca pumping into isolated bovine disks, which may be the result of energy-dependent Ca transport (Puckett et al., 1985). The maximal rate of ATP-dependent uptake $(0.013 \mathrm{Ca} / \mathrm{Rh} / \mathrm{min}$ or $8 \times 10^{5} \mathrm{Ca} / \mathrm{rod} / \mathrm{sec}$ for toad at $24^{\circ} \mathrm{C}$ ) would be sufficient to 
account for the rates of uptake which we have observed in isolated retina.

Figure 10 emphasizes a central feature of our interpretation, namely, that $\mathrm{Ca}$ in the cytoplasm and $\mathrm{Ca}$ in the disk are separated from one another by the disk membrane and that exchange between these 2 pools occurs slowly in the absence of a specific increase in $\mathrm{Ca}$ permeability or transport across the disk. Although we have indicated $\mathrm{Ca}_{\text {disk }}$ as if it consisted of a single population of $\mathrm{Ca}$ ions, our experiments suggest that this may not be the case. Long exposures even to bright illumination only release one-half to two-thirds of the Ca sequestered within the outer segment (Schröder and Fain, 1984a). This would suggest that the sequestered $\mathrm{Ca}$ is further subdivided into $\mathrm{Ca}$ which is releasable by light and Ca which is not.

When, after bright light exposure, ${ }^{44} \mathrm{Ca}$ is taken back up into the outer segment in darkness, a part of it must enter the lightreleasable pool, since the ${ }^{44} \mathrm{Ca}$ content of the rod decreases upon re-illumination (Fig. 8). However, re-illumination also releases a fraction of the ${ }^{40} \mathrm{Ca}$ remaining in the rod. It is of some interest that the sum of the ${ }^{40} \mathrm{Ca}$ and ${ }^{44} \mathrm{Ca}$ released in bright light at the end of the experiment in both Figure $8 A$ and $8 B$ is approximately equal to the quantity of ${ }^{44} \mathrm{Ca}$ which entered the outer segment during the preceeding incubation in darkness. This would suggest that some exchange occurs between the lightreleasable and nonreleasable pools. It is possible that only a portion of the $\mathrm{Ca}$ in the disk is light-releasable because some of the $\mathrm{Ca}$ is bound to sites of high affinity and some is not. It is also possible that the release of a part of the disk Ca crcatcs a potential difference across the disk membrane which impedes further efflux.

\section{Ca release and re-uptake in the presence of the pigment epithelium}

Measurements from rods exposed to light in an eyecup preparation, for which the outer segments were in contact with the $\mathrm{RPE}$, show that $\mathrm{Ca}$ is released with a time course indistinguishable from that in isolated retina (Fig. $2 B$ ). Re-uptake of $\mathrm{Ca}$, however, occurs considerably faster in the eyecup (Fig. 9). The reason for this difference is unclear. It is possible that the rods are simply maintained in a more robust condition in the eyecup. Another possibility is that the RPE, which has been shown to transport Ca from the sclera to the interphotoreceptor space (Miller and Steinberg, 1977), is able to increase the concentration of free $\mathrm{Ca}$ in the extracellular medium adjaccnt to the outer segments. This might have the effect of increasing the rate of transport of Ca into the disks. Finally, the RPE plays an important role in the regeneration of visual pigment, and it is possible that regeneration of rhodopsin must take place in order for $\mathrm{Ca}$ to be restored to the disks. This possibility seems the least likely of the ones we have mentioned, since the results in Figure 9 indicate that re-uptake is enhanced by RPE even after exposure to light, which we calculate to have bleached only $0.1-$ $1 \%$ of the visual pigment. At such dim intensities, considerable regeneration has been shown to occur even in the isolated retina (see, for example, Cocozza and Ostroy, 1987).

\section{Role of light-dependent Ca release in the physiology of photoreceptors}

The results from our experiments make it unlikely that $\mathrm{Ca}$ relcase from the rods plays any direct role either in excitation or in sensitivity modulation during continuous light exposure (light adaptation). Dim light intensities produce a $\mathrm{Ca}$ release which is maintained but small by comparison to the decrease in $\mathrm{Ca}$ influx through the light-dependent channels. It is therefore unlikely that the $\mathrm{Ca}$ release we have measured plays a major role in controlling cytosolic $\mathrm{Ca}^{2+}$ concentration. Bright light releases considerably more $\mathrm{Ca}$, but this release occurs only after a delay of several seconds and is transient. Furthermore, the Ca once released is restored to its dark-adapted level slowly, even in the presence of the pigment epithelium.

Since large amounts of $\mathrm{Ca}$ are released from the rod in bright light, and since the $\mathrm{Ca}$ is returned to the outer segments after the light is turned off, during dark adaptation, it is possible that Ca relcasc and re-uptakc is in somc way involved in the changes in sensitivity produced by photopigment bleaching and recovery. Our data seem inconsistent with a simple relationship between sensitivity and the total amount of $\mathrm{Ca}$ in the rod, since the rate of $\mathrm{Ca}$ re-uptake in isolated retina is indistinguishable following a $1 \%$ (Fig. 7) and $20 \%$ bleach (Fig. $8 B$ ), but the rate of sensitivity recovery is different after these light exposures (see, for example, Grabowski and Pak, 1975). Furthermore, the recovery of $\mathrm{Ca}$ seems to occur much more slowly than the recovery of sensitivity, for example, after a $0.1 \%$ bleach (Figs. $8 \mathrm{~A}$, $9 A$ ). It remains possible that sensitivity is related to $\mathrm{Ca}$ release and re-uptake in some more complicated way, or that sensitivity is regulated not by the total $\mathrm{Ca}$ in the outer segment but rather by the free Ca concentration in the disk. It is also possible that $\mathrm{Ca}$ is not responsible for sensitivity recovery but for some other process which is triggered by bright light. The study of longterm changes in sensitivity and metabolism in photoreceptors may eventually clarify the function of light-dependent $\mathrm{Ca}$ release and re-uptake in the physiology of the rod.

\section{References}

Bastian BL, Fain GL (1979) Light adaptation in toad rods: requirement for an internal messenger which is not calcium. J Physiol (Lond) 297: 493-520.

Burgess GM, McKinney JS, Fabiato A, Leslie BA, Putney JW Jr (1983) Calcium pools in saponin-permeabilized guinea pig hepatocytes. $J$ Biol Chem 258:15336-15345.

Cervetto L, Lagnado L, Perry RJ, Robinson DW, McNaughton PA (1989) Extrusion of calcium from rod outer segments is driven by both sodium and potassium gradients. Nature 337:740-743.

Cocozza JD, Ostroy SE (1987) Factors affecting the regeneration of rhodopsin in the isolated amphibian retina. Vision Res 27:10851091.

Fain GL (1976) Sensitivity of toad rods: dependence on wave-length and background illumination. J Physiol (Lond) 261:71-101.

Fain GL, Schröder WH (1985) Calcium content and calcium exchange in dark-adapted toad rods. J Physiol (Lond) 368:641-665.

Fain GL, Schröder WH (1987) Calcium in dark-adapted toad rods: evidence for pooling and cyclic-guanosine-3'-5'-monophosphate-dependent release. J Physiol (Lond) 389:361-384.

Fain GL, Lamb TD, Matthews HR, Murphy RLW (1989) Cytoplasmic calcium concentration as the messenger for light adaptation in salamander rods. J Physiol (Lond) 416:215-243.

Fein A, Szuts EZ (1982) Photoreceptors, their role in vision. Cambridge, UK: Cambridge University Press.

Fesenko EE, Kolesnikov SS, Lyubarsky AL (1985) Induction by cyclic GMP of cationic conductance in plasma membrane of retinal rod outer segment. Nature 313:310-313.

Gold GH (1986) Plasma membrane calcium fluxes in intact rods are inconsistent with the "calcium hypothesis." Proc Natl Acad Sci USA 83:1150-1154.

Gold GH, Korenbrot JI (1980) Light-induced calcium release by intact retinal rods. Proc Natl Acad Sci USA 77:5557-5561.

Grabowski SR, Pak WL (1975) Intracellular recordings of rod responses during dark-adaptation. J Physiol (Lond) 247:363-391.

Hirata M, Koga T (1982) ATP-dependent $\mathrm{Ca}^{2+}$ accumulation into 
intracellular membranes of guinea pig macrophages after saponin treatment. Biochem Biophys Res Commun 104:1544-1549.

Hodgkin AL, Nunn BJ (1988) Control of light-sensitive current in salamander rods. J Physiol (Lond) 403:439-471.

Hodgkin AL, McNaughton PA, Nunn BJ (1985) The ionic selectivity and calcium dependence of the light-sensitive pathway in toad rods. J Physiol (Lond) 358:447-468.

Hodgkin AL, McNaughton PA, Nunn BJ (1987) Measurement of sodium-calcium exchange in salamander rods. J Physiol (Lond) 391: 347-370.

Koch K-W, Stryer L (1988) Highly cooperative feedback control of retinal rod guanylate cyclase by calcium ions. Nature 334:64-66.

Lagnado L, Cervetto L, McNaughton PA (1988) Ion transport by the $\mathrm{Na}-\mathrm{Ca}$ exchange in isolated rod outer segments. Proc Natl Acad Sci USA 85:4548-4552.

Lamb TD (1980) Spontaneous quantal events induced in toad rods by pigment bleaching. Nature 287:349-351.

Lamb TD (1986) Transduction in vertebrate photoreceptors: the roles of cyclic GMP and calcium. Trends Neurosci 9:224-228.

Matthews, G, Watanabe S-I (1987) Properties of ion channels closed by light and opened by guanosine $3^{\prime}, 5^{\prime}$ cyclic monophosphate in toad retinal rods. J Physiol (Lond) 389:691-715.

Matthews HR, Murphy RLW, Fain GL, Lamb TD (1988) Photoreceptor light adaptation is mediated by cytoplasmic calcium concentration. Nature 334:67-69.

McNaughton PA, Cervetto I, Nunn BJ (1986) Measurement of the intracellular free calcium concentration in salamander rods. Nature 322:261-263.

Miller DL, Korenbrot JI (1987) Kinetics of light-dependent Ca fluxes across the plasma membrane of rod outer segments: a dynamic model of the regulation of cytoplasmic Ca concentration. J Gen Physiol 90: $397-425$.

Miller SS, Steinberg RH (1977) Active transport of ions across frog retinal pigment epithelium. Exp Eye Res 25:235-248.

Nakatani K, Yau K-W (1988a) Calcium and magnesium fluxes across the plasma membrane of the toad rod outer segment. J Physiol (Lond) 395:695-729.

Nakatani K, Yau K-W (1988b) Guanosine 3',5'-cyclic monophosphate-activated conductance studied in a truncated rod outer segment of the toad. J Physiol (I ond) 395:731-753.

Nakatani K, Yau K-W (1988c) Calcium and light adaptation in retinal rods and cones. Nature 334:69-71.

Nicol GD, Kaupp UB, Bownds MD (1987) Transduction persists in rod photoreceptors after depletion of intracellular calcium. J Gen Physiol 89:297-319.

Puckett KL, Aronson ET, Goldin SM (1985) ATP-dependent Ca uptake activity associated with a disc membrane fraction isolated from bovine retinal rod outer segments. Biochemistry 24:390-400.
Ratto GM, Payne R, Owen WG, Tsien RY (1988) The concentration of cytosolic free $\mathrm{Ca}^{2+}$ in vertebrate rod outer segments measured with fura2. J Neurosci 8:3240-3246.

Robinson PR, Kawamura S, Abramson B, Bownds MD (1980) Control of the cyclic GMP phosphodiesterase of frog photoreceptor membranes. J Gen Physiol 76:631-645.

Schnetkamp PPM (1980) Ion selectivity of the cation transport system of isolated intact cattle rod outer segments. Evidence for a direct communication between the rod plasma membrane and the rod disk membranes. Biochim Biophys Acta 598:66-90.

Schnetkamp PPM (1986) Sodium-calcium exchange in the outer segments of bovine rod photoreceptors. J Physiol (Lond) 373:25-45.

Schröder WH, Fain GL (1984a) Light-dependent calcium release from photoreceptors measured by laser micro mass analysis. Nature 309 : 268-270.

Schröder WH, Fain GL (1984b) Light-dependent release of Ca from rods measured by laser micro mass analysis. Biophys $\mathrm{J} 45: 341$ a.

Schröder WH, Fain GL (1987) Light-activated Ca release and reuptake in rods. Invest Ophthalmol Vis Sci (Suppl) 28:95.

Tiffert T, Brindley FJ Jr (1981) In situ accumulation of calcium by organelles of squid axoplasm. Cell Calcium 2:89-104.

Torre V, Matthews HR, Lamb TD (1986) Role of calcium in regulating the cyclic GMP cascade of phototransduction in retinal rods. Proc Natl Acad Sci USA 83:7109-7113.

Vogt H, Heinen HJ, Meier S, Wechsung R (1981) LAMMA 500 Principle and technical description of the instrument. Fresenius $Z$ Anal Chem 308:195-200.

Weast RC (1970) Handbook of chemistry and physics, 51 st ed. Cleveland, $\mathrm{OH}$ : Chemical Rubber Co.

Wechsung R, Hillenkamp F, Kaufmann R, Nitsche R, Vogt H (1979) LAMMA - a new laser microprobe. In: Scanning electron microscope, Vol 1 (O'Hare AMF, ed), pp 611-620. Chicago: SEM Inc.

WoodruffML, Fain GL, Bastian BL (1982) Light-dependent ion influx into toad photoreceptors. J Gen Physiol 80:517-536.

Yau K-W, Nakatani K (1984a) Cation selectivity of light-sensitive conductance in retinal rods. Nature 309:352-354.

Yau K-W, Nakatani K (1984b) Electrogenic Na-Ca exchange in retinal rod outer segment. Nature 311:661-663.

Yau K-W, Nakatani K (1985) Light-induced reduction of cytoplasmic free calcium in retinal rod outer segment. Nature 313:579-582.

Yoshikami S, Hagins WA (1971) Light, calcium, and the photocurrent of rods and cones. Biophys J 11:47a.

Yoshikami S, George JS, Hagins WA (1980) Light-induced calcium fluxes from outer segment layer of vertebrate retinas. Nature 286 : 395-398. 